Article

\title{
Persistent Hot Spot Detection and Characterisation Using SLSTR
}

\author{
Alexandre Caseiro ${ }^{1, *} \mathbb{D}$, Gernot Rücker ${ }^{2}$, Joachim Tiemann ${ }^{2}$, David Leimbach ${ }^{2}$, \\ Eckehard Lorenz $^{3}$, Olaf Frauenberger ${ }^{4}(\mathbb{D})$ and Johannes W. Kaiser ${ }^{1}$ (D) \\ 1 Max Planck Institute for Chemistry, 55128 Mainz, Germany; j.kaiser@mpic.de \\ 2 Zebris GbR, 81373 Munich, Germany; gruecker@zebris.com (G.R.); jtiemann@zebris.com (J.T.); \\ dleimbach@zebris.com (D.L.) \\ 3 DLR, 12489 Berlin, Germany; eckehard.lorenz@dlr.de \\ 4 DLR, 17235 Neustrelitz, Germany; olaf.frauenberger@dlr.de \\ * Correspondence: alexandre.caseiro@mpic.de; Tel.: +49-6131-305-4071
}

Received: 30 April 2018; Accepted: 5 July 2018; Published: 13 July 2018

\begin{abstract}
Gas flaring is a disposal process widely used in the oil extraction and processing industry. It consists in the burning of unwanted gas at the tip of a stack and due to its thermal characteristic and the thermal emission it is possible to observe and to quantify it from space. Spaceborne observations allows us to collect information across regions and hence to provide a base for estimation of emissions on global scale. We have successfully adapted the Visible Infrared Imaging Radiometer Suite (VIIRS) Nightfire algorithm for the detection and characterisation of persistent hot spots, including gas flares, to the Sea and Land Surface Temperature Radiometer (SLSTR) observations on-board the Sentinel-3 satellites. A hot event at temperatures typical of a gas flare will produce a local maximum in the night-time readings of the shortwave and mid-infrared (SWIR and MIR) channels of SLSTR. The SWIR band centered at $1.61 \mu \mathrm{m}$ is closest to the expected spectral radiance maximum and serves as the primary detection band. The hot source is characterised in terms of temperature and area by fitting the sum of two Planck curves, one for the hot source and another for the background, to the radiances from all the available SWIR, MIR and thermal infra-red channels of SLSTR. The flaring radiative power is calculated from the gas flare temperature and area. Our algorithm differs from the original VIIRS Nightfire algorithm in three key aspects: (1) It uses a granule-based contextual thresholding to detect hot pixels, being independent of the number of hot sources present and their intensity. (2) It analyses entire clusters of hot source detections instead of individual pixels. This is arguably a more comprehensive use of the available information. (3) The co-registration errors between hot source clusters in the different spectral bands are calculated and corrected. This also contributes to the SLSTR instrument validation. Cross-comparisons of the new gas flare characterisation with temporally close observations by the higher resolution German FireBIRD TET-1 small satellite and with the Nightfire product based on VIIRS on-board the Suomi-NPP satellite show general agreement for an individual flaring site in Siberia and for several flaring regions around the world. Small systematic differences to VIIRS Nightfire are nevertheless apparent. Based on the hot spot characterisation, gas flares can be identified and flared gas volumes and pollutant emissions can be calculated with previously published methods.
\end{abstract}

Keywords: gas flaring; SLSTR

\section{Introduction}

Gas flaring (GF) is part of the upstream oil and gas industry processes as a means of disposing of unwanted natural gas through high temperature oxidation at the tip of a stack. GF is a problem of local 
and global concern. GF impacts the local environment [1] through: noise [2,3], visual pollution [4,5], heat stress $[4,6]$ and the emission of air pollutants like black carbon, polycyclic aromatic hydrocarbons, volatile organic compounds and acid rain precursors [7-10]. Flaring produces greenhouse gases (GHG) and black carbon as the main by-products of the combustion. In terms of the global GHG budget gas flaring produced an estimated yearly average emission of $304 \mathrm{Tg} \mathrm{CO}_{2}$ between 2003 and 2012, representing $0.6 \%$ of the global carbon dioxide equivalent anthropogenic emissions [11]. Regarding the short-lived climate forcer black carbon, GF may be of regional prime importance. GF has been identified as the main input of black carbon in boreal regions [12,13], with implications for the albedo of snow-covered surfaces, the earth's radiative balance [14,15] and the Arctic amplification phenomenon [16], being therefore of global relevance [17]. Again in the Arctic region, GF's contribution to the $\mathrm{NO}_{2}$ concentrations is important, and has been increasing in the past decade [18].

The information on flared volumes and emissions is sparse and methodologically inconsistent due to technical difficulties and the lenient reporting requirements and guidelines of some jurisdictions. Since GF creates a persistent or intermittent thermal signal, remote sensing offers the possibility of a globally consistent and independent monitoring of flaring. Important applications of GF monitoring are the estimation of the burnt gas volume in billion cubic metres (BCM) and the pollutant emissions to the atmosphere. Such estimations have already been performed with the help of a conversion factor that scales observed radiative energy release to $\mathrm{BCM}$ and emission factors that convert BCM into the amount of different chemical smoke species [19]. The emission factors have been measured in situ and reported in the literature [20-22]. The conversion factor has been calculated as fraction of reported BCM and the observed radiative energy in entire countries [19], at the regional scale or for individual flares $[23,24]$.

The identification of flaring in the night-time observations in the visual and near infra-red (Vis-NIR) spectral range $[25,26]$ allowed for the first semi-automatic monitoring of flares from space [27-29]. With the advent of vegetation fire detection products based on mid and thermal infrared bands (MIR and TIR), flaring was highlighted as a main source of false alarms [30,31]. This feature was exploited to study flaring $[32,33]$ and later the additional evaluation of short-wave infrared (SWIR) bands allowed for a more accurate detection [19,34-37], which is the current state-of-the-art.

Algorithms exploiting the IR part of the spectrum for flare detection and characterisation have been developed for several sensors. Casadio et al. [35] considered the radiances at four wavelengths (in the SWIR, MIR and TIR bands of (A)ATSR, (Advanced) Along Track Scanning Radiometer) to be a linear combination of black body radiances from two areas with different temperatures within the satellite pixel footprint (actively flaming and background). Besides using the $1.61 \mu \mathrm{m}$ channel for the detection, the authors also discriminated between persistent (at least 4 detections a year at a given location) and non-persistent signals, and attributed persistent detections to gas flaring. Elvidge et al. [36] developed the Nightfire algorithm, in which a Planck curve is fitted to the night-time Vis-IR measurements of the Visible Infrared Imaging Radiometer Suite instrument (VIIRS, on-board the Suomi-National Polar Partnership satellite) to retrieve the hot spot temperature. They considered an emission scaling factor to estimate the flare size. The methodology was further developed into a dual Planck curve fitting (for the background and the flare) to the observations in five bands (NIR, SWIR and MIR) of VIIRS [19]. It was used to retrieve information on the global distribution and characteristics of gas flaring and the results are made public by NOAA's National Centre for Environmental Information as daily global fields (https: / /ngdc.noaa.gov / eog/viirs/download_viirs_fire.html). It was later demonstrated that the SWIR radiance could be used by itself to estimate the flaring radiative power [38]. Gas flaring in Africa was also monitored using Landsat [37] and MODIS [23] imagery. The former algorithm used a thresholds series for the NIR, SWIR and TIR bands, and the latter used a combination of a fixed threshold and spatial filtering. The BIRD algorithm was developed to apply the bi-spectral method [39] to MIR and TIR data from the Hot Spot Recognition System (HSRS) instrument on board the bi-spectral Infrared Detection (BIRD) Experimental Small Satellite (2001-04) [40-42]. It was designed to retrieve effective temperature, effective area and effective radiative power of sub-pixel hot sources, namely 
fires $[43,44]$. The methodology was later ported to the successor FireBIRD mission, with a similar sensor in IR and a modified Vis-NIR payload on board of the TET-1 (Technologieerprobungsträger-1) spacecraft [45].

The Sea and Land Surface Temperature Radiometer (SLSTR) instrument on board ESA's Sentinel-3 features night-time observations in two SWIR (S5: $1.61 \mu \mathrm{m}$ and S6: $2.25 \mu \mathrm{m}$ ), one MIR (S7: $3.74 \mu \mathrm{m})$ and two TIR bands (S8: $10.85 \mu \mathrm{m}$ and S9: $12.0 \mu \mathrm{m}$ ). The instrument also measures in two fire-dedicated bands (F1: $3.74 \mu \mathrm{m}$ and F2: $10.85 \mu \mathrm{m}$ ) with the same central wavelength and band width as S7 and S8, but extended dynamical ranges to prevent saturation over active fires [46]. The distribution of the SLSTR spectral channels with SWIR, MIR and 2 channels in TIR should allow for the detection and characterisation of GF and other hot spots via the SWIR detection and dual Planck curve fitting methodology. Compared to VIIRS, SLSTR is observing in one additional SWIR channel at night-time and it has better signal-to-noise requirements $[47,48]$. SLSTR can therefore be expected to detect even smaller and cooler hot targets than VIIRS. However, SLSTR is missing the observations in the visible spectral range, i.e., VIIRS' DNB channel, which may make the temperature retrieval less accurate. Furthermore, the long-term commitment of the EU Copernicus programme, which funds the Sentinel satellites, would warrant data availability well into the 2030s.

In this paper, we present a new algorithm for the detection and characterisation of persistent hot spots, including gas flares, detection and characterization from SLSTR observations and apply it to actual SLSTR data. Section 2 presents the data used. Section 3 describes the developed methodology in detail. In Section 4 we present the results of the application of the newly developed algorithm at the regional level in four regions of interest (West Africa, The North and Caspian Seas and the Persian Gulf) and evaluate our methodology against the VIIRS Nightfire product. The performance of our algorithm is further evaluated against VIIRS Nightfire and retrievals based on HSRS on-board the German small satellite TET-1 at the level of a single gas flaring site on the Yamal peninsula, Northern Siberia. Finally, in Section 5 we present our conclusions.

\section{Data}

SLSTR Level $1 b$ version 2 products obtained from the ESA's Sentinel Expert User's Hub in January 2017 were used for this work. The downloaded products were selected using a geographic criterion (four regions of interest: West Africa, the Caspian and the North Seas and the Persian Gulf) and a time of day criteria (only night-time acquisitions). The products were sampled in the second half of 2016. For the SWIR bands (S5 and S6), the data available in the product are top of the atmosphere (TOA) radiances, while for the MIR (S7 and F1) and TIR (S8, S9 and F2) bands, the available data are brightness temperatures. The latter were converted back to TOA radiances using lookup tables provided by the European Space Agency.

FireBird TET-1 level-2 co-registered data of TET-1 night time acquisition mode (only MIR and TIR bands at $170 \mathrm{~m}$ spatial resolution) were obtained for near coincident or temporally close SLSTR and TET-1 observations during polar night conditions in 2016/17 over the Yamal peninsula and other areas in Northern Siberia. Due to solar light contamination, only data North of about $70^{\circ}$ latitude could be used, which excluded the other regions. Probably due to the extremely cold background, the standard level-2 fire processor of FireBird [45] failed to identify valid background pixels, and thus did not detect any hot clusters. The co-registered data were therefore reprocessed with the BIRD night-time algorithm [42] which was adapted to the spatial resolution of TET-1 and the cold background. The algorithm for fire detection and characterisation output includes an estimate of the fire area together with their uncertainties [42] which were used for comparison with the temporally close SLSTR retrievals. The BIRD algorithm artificially sets the upper temperature bounds to $1500 \mathrm{~K}$ to avoid unrealistically high bi-spectral retrievals in the case of overestimations of the TIR background radiance. This limit was adjusted to $2000 \mathrm{~K}$ to account for the higher temperature of gas flares within this study.

VIIRS Nightfire data [36] were downloaded from the NOAA website. No further processing was applied to this dataset. 
Table 1 summarizes the specifications of the used sensors, while Table 2 summarizes the data used.

Table 1. Comparison between the used sensors.

\begin{tabular}{|c|c|c|c|}
\hline & $\begin{array}{c}\text { HSRS } \\
\text { on TET-1 }\end{array}$ & $\begin{array}{c}\text { VIIRS } \\
\text { on Suomi-NPP }\end{array}$ & $\begin{array}{c}\text { SLSTR } \\
\text { on Sentinel-3A }\end{array}$ \\
\hline Start of operation & 2013 & 2011 & 2016 \\
\hline $\begin{array}{c}\text { Orbit } \\
\text { altitude }(\mathrm{km})\end{array}$ & $\begin{array}{c}\text { Sun synchronous } \\
445\end{array}$ & $\begin{array}{c}\text { Sun synchronous } \\
834\end{array}$ & $\begin{array}{c}\text { Sun synchronous } \\
814.5\end{array}$ \\
\hline $\begin{array}{l}\text { Vis-NIR bands } \\
\qquad(\mu \mathrm{m})\end{array}$ & & $\begin{array}{l}\text { DNB: } 0.5-0.9 \\
\text { M7: } 0.85-0.89 \\
\text { M8: } 1.23-1.25\end{array}$ & \\
\hline $\begin{array}{l}\text { SWIR bands } \\
(\mu \mathrm{m})\end{array}$ & & M10: 1.58-1.64 & $\begin{array}{l}\text { S5: } 1.58-1.65 \\
\text { S6: } 2.23-2.28\end{array}$ \\
\hline $\begin{array}{l}\text { Infrared } \\
\text { bands } \\
(\mu \mathrm{m})\end{array}$ & $\begin{array}{l}\text { MIR: } 3.40-4.20 \\
\text { TIR: } 8.50-9.30\end{array}$ & $\begin{array}{c}\text { M12: } 3.55-3.93 \\
\text { M13: } 3.97-4.13 \\
\text { M15: } 10.26-11.26\end{array}$ & $\begin{array}{c}\text { S7, F1: 3.55-3.93 } \\
\text { S8: 10.40-11.30 } \\
\text { S9, F2: } 11.50-12.50\end{array}$ \\
\hline $\begin{array}{c}\text { Ground } \\
\text { resolution (m) }\end{array}$ & IR-bands: 170 & M-bands: 750 & $\begin{array}{c}\text { S4-S6: } 500 \\
\text { S7-S9, F1-F2: } 1000\end{array}$ \\
\hline Swath (km) & IR: 178 & 3040 & 1420 \\
\hline
\end{tabular}

Table 2. Data used in this study. The number of VIIRS products was derived from the VIIRS Nightfire dataset from NOAA, corresponding to the products which exhibited detections co-located in space and time.

\begin{tabular}{ccccc}
\hline & Sensor & Region & Sampling Dates & $n$ \\
\hline \multirow{4}{*}{$\begin{array}{c}\text { Regional } \\
\text { study }\end{array}$} & SLSTR & North Sea & 17 November-18 December 2016 & 189 \\
& & Persian Sea & 17 November-20 December 2016 & 99 \\
& & West Africa & 17 November-31 December 2016 & 153 \\
& VIIRS (Nightfire) & Global & 25 July-29 September 2016 & 364 \\
Single site & SLSTR & Yamal & 15 December 2016 & 587 \\
study & VIIRS (Nightfire) & peninsula & - & 43 \\
& HSRS & & 2 January 2017 & 12 \\
\hline
\end{tabular}

\section{Methodology}

A general flowchart of the developed methodology is shown in Figure 1. The individual processing steps are described in the following sections. 


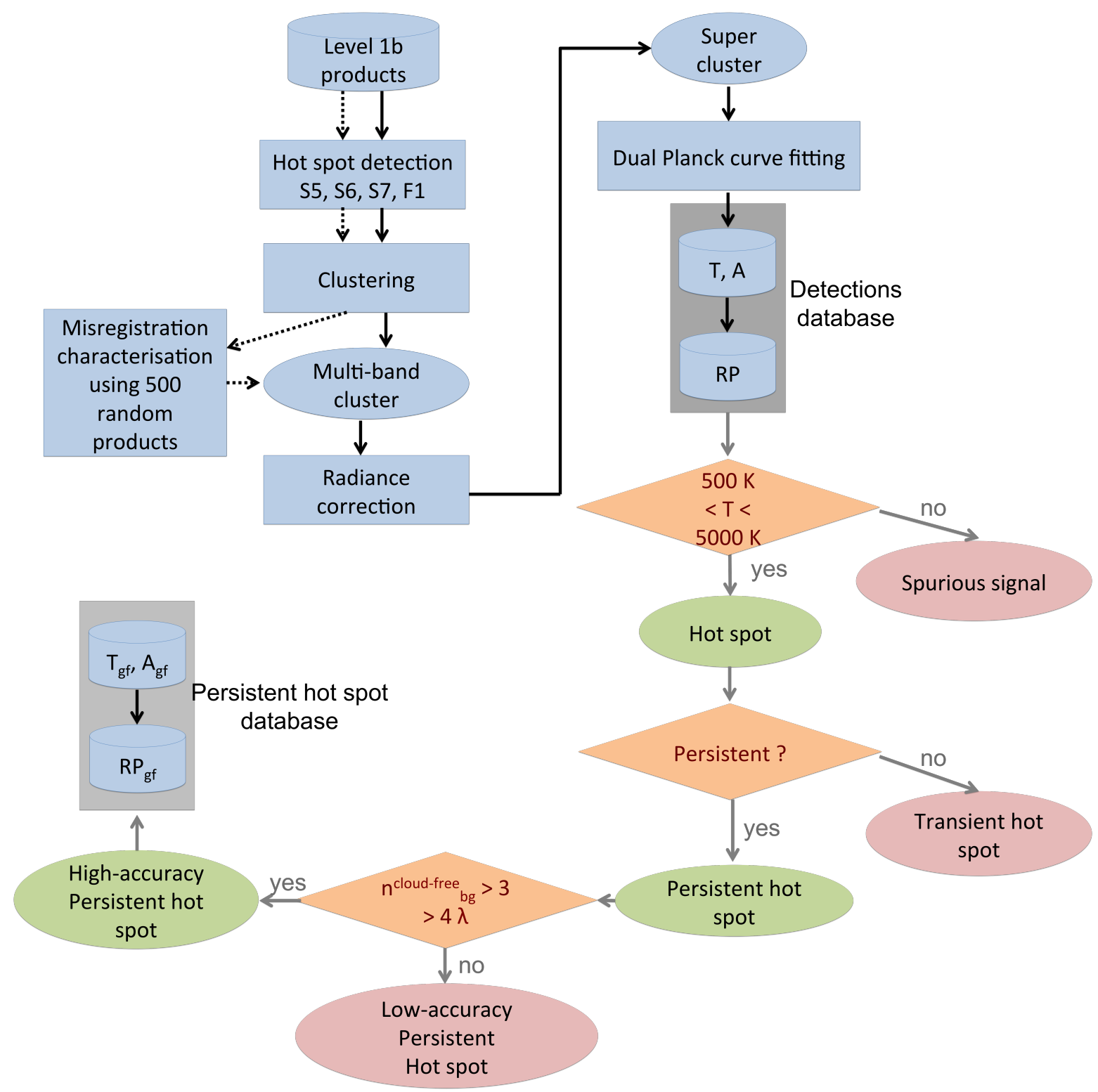

Figure 1. General algorithm flowchart for the detection of persistent hot spots and their characterisation: temperature $(\mathrm{T})$, area $(\mathrm{A})$ and radiative power $(\mathrm{RP})$. The dotted line represents the one-time misregistration determination. The parameterization was then used when building the multi-band cluster. $n_{b g}^{\text {cloud-free }}>3$ represents at least three cloud-free pixels in the background. $>4 \lambda$ means there is radiance data at least 4 of the 5 wavelengths considered by the algorithm. We do not believe spurious signals are hot sources, but noise such as e.g., lunar reflection or the Southern Atlantic anomaly. Transient hot spots are e.g., vegetation fires. Persistent hot spots are e.g., gas flares, volcanoes, industry. We believe low accuracy persistent hot spots are hot sources, but the fitted parameters (T and A), and therefore RP, are relatively uncertain.

\subsection{Detection}

The SLSTR SWIR channels S5 and S6 capture the peak radiation of typical industrial (1100-1500 K) and gas flaring temperatures (around $1800 \mathrm{~K}$ ) [19,49,50] as given by the Planck equation (Figure 2). The ability of SLSTR to detect hot spots in the SWIR and MIR bands was evaluated according to the instrument's requirements and is shown in Figure 3 and compared to VIIRS. In the $1.6 \mu \mathrm{m}$ channel, SLSTR is expected to perform similarly as VIIRS. VIIRS does not record in the $2.25 \mu \mathrm{m}$ channel at night. In the $3.7 \mu \mathrm{m}$ channels, VIIRS shows more sensitivity to cooler hot spots but SLSTR is, thanks to the 
extended dynamic range of F1 which complements S7, theoretically able to quantify larger and hotter hot spots.

Remote detection of gas flares with space-borne SWIR observations has been using a priori fixed thresholds on one or several bands $[34,35,37]$ or determining the threshold based on the pixel's surroundings, i.e., contextual thresholding $[19,23,36]$. In the present work, we use contextual thresholding. Due to the representation of the observations as digital numbers (DN) in the satellite downlink, all radiance values within a single scene are multiples of a fixed radiance value, i.e., a step size $s f_{\lambda}$. This is clearly visible in the top-left panel of Figure 4. For each scene and channel, we determine the threshold radiance $B_{\lambda}^{\text {threshold }}$ as the lowest multiple of the step size that is not reported for any pixel:

$$
B_{\lambda}^{\text {threshold }}=\min \left\{B_{\lambda, i}^{\text {largest }} \mid B_{\lambda, i}^{\text {largest }}-B_{\lambda, i-1}^{\text {largest }}>s f_{\lambda}\right\}
$$

where $B_{\lambda}^{\text {largest }}=\left\{B_{\lambda,-999}, \ldots, B_{\lambda, 0} \mid B_{\lambda, i} \leq B_{\lambda, i+1}\right\}$ is the ordered set of the 1000 largest radiances in the granule (typically SWIR bands: $2400 \times 3000$ pixels per granule, MIR and TIR bands: $1200 \times 1500$ pixels per granule), and $s f_{\lambda}$ is the scale factor for the product and that band, which is calculated from the smallest interval between the recorded values. Radiance values below the threshold are interpreted as smoothly varying background plus "typical" noise, while radiance values above the threshold are interpreted as potential hot spot detections and are processed further.

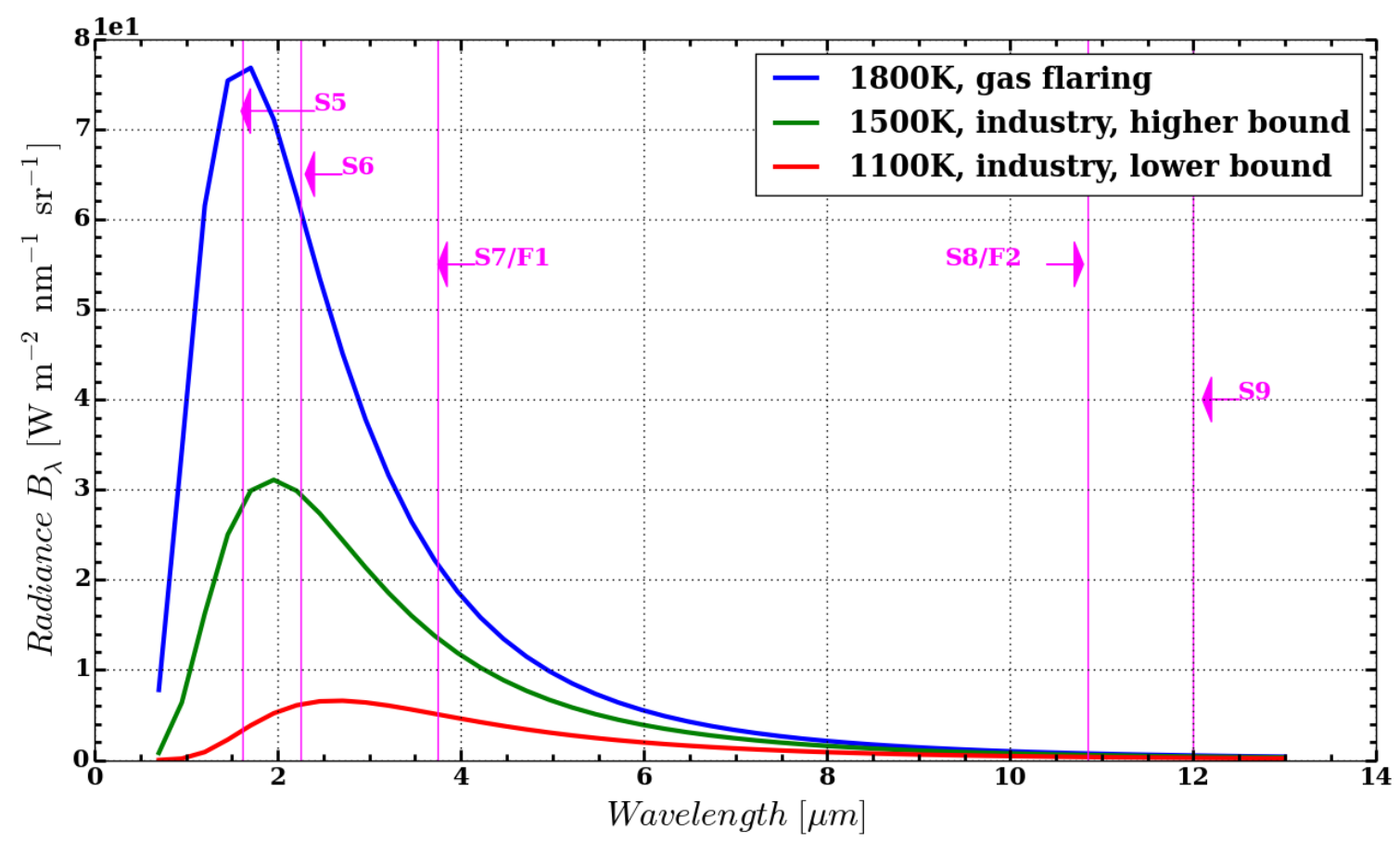

Figure 2. Planck curves for typical industrial processes and gas flaring temperatures, together with SLSTR SWIR (S5 and S6), MIR (S7 and F1) and TIR (S8, S9 and F2) channels. Temperatures of $1100 \mathrm{~K}$ and $1500 \mathrm{~K}$ represent, roughly, the lower and upper bounds of the operating temperatures of blast furnaces. $1800 \mathrm{~K}$ is a typical gas flaring temperature. 

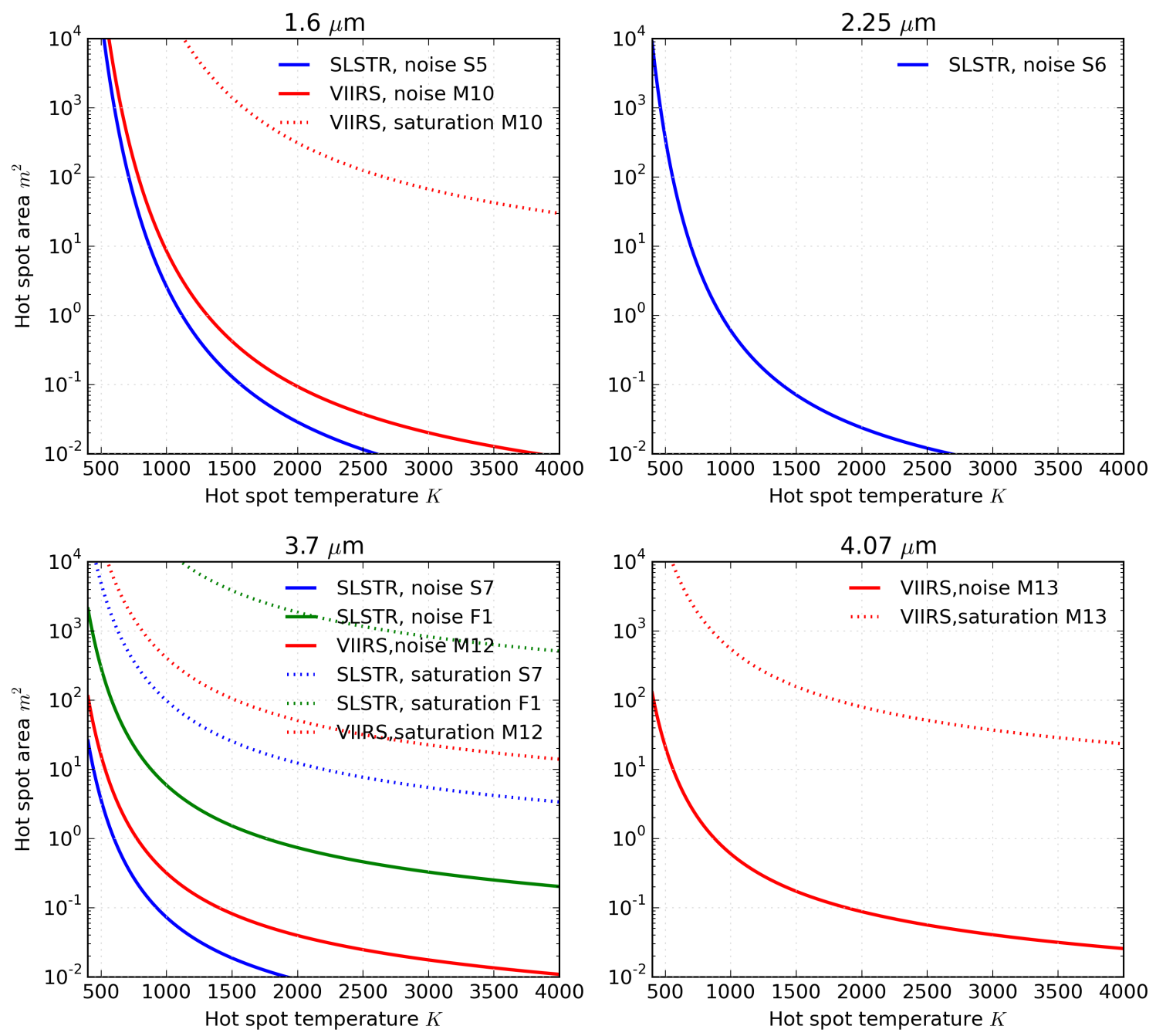

Figure 3. Isoradiance lines for the noise (SWIR bands S5 and S6 and MIR bands S7 and F1) and saturation levels (MIR bands S7 and F1) for SLSTR and noise and saturation for the SWIR and MIR bands (M10, M12 and M13) of VIIRS used in the Nightfire algorithm. The SLSTR noise levels were computed using the End-of-Life noise-equivalent differential reflectance (S5 and S6) and noise-equivalent differential temperature levels (S7 and F1) [47] and were $1.5 \times 10^{-2}, 8.4 \times 10^{-3}$, $2.6 \times 10^{-4}$ and $2.1 \times 10^{-1} \mathrm{~W} \mathrm{~m}^{-2} \mu^{-1} \mathrm{sr}^{-1}$ for S5, S6, S7 and F1 respectively. A reflectance of $30 \%$ as given in the original works [47] was considered, together with irradiance data from SCIAMACHY http://www.iup.uni-bremen.de/UVSAT/Datasets/solar-reference-data [51], to compute the noise levels. A background temperature of $285 \mathrm{~K}$ is assumed. Noise and saturation for VIIRS bands were computed using the signal-to-noise ratios given by Cao et al. [48]. Brightness temperature to radiance conversions were all computed using Planck's law. Temperatures between $600 \mathrm{~K}$ and $1500 \mathrm{~K}$ represent, roughly, the lower and upper bounds for biomass burning, volcanoes and industrial sources. The range $1300-2000 \mathrm{~K}$ is typical for gas flaring temperatures [19].

We have tested several other approaches on the ordered set of the radiances of a product:

- The cut-off value was set as the lowest radiance which produced two statistically distinct groups (using the Mann-Whitney-Wilcoxon U-test). This approach failed to produce thresholds for the majority of products.

- The cut-off value was the lowest radiance which was not included within the confidence interval of the linear regression of the previous points. This methodology lead to the inclusion of irrealistically low radiance pixels as hot pixels and the subsequent production of extremely large clusters. 
- Also based on the linear regression, we examined where the slope changed significantly and whether that point could be used as a threshold. This was highly dependent on the assumptions on the linear regression and considered as non robust.

- Otsu's method [52] produced large thresholds and therefore left out real hot spots.

- An iterative clustering method which minimized differences between radiances of data points within two clusters also lead to large thresholds.

- Based on the fact that the night-time background is rather homogenous, the variance of the radiances of the product should be increased strongly by hot spots, while the background pixels should have a small variance. This approach was very sensitive on the a priori explained variance expected and was therefore abandoned.

The selected approach was the most robust, identifying hot pixels in different contexts with low variation between different products. This approach captures hot pixels when there is a gradual or an abrupt increase (upper and lower plots of Figure 4, respectively). While not fixed, and therefore adaptable to product-specific conditions, this contextual methodology is not statistical and therefore not directly sensitive to the number of hot events sampled and their intensity.
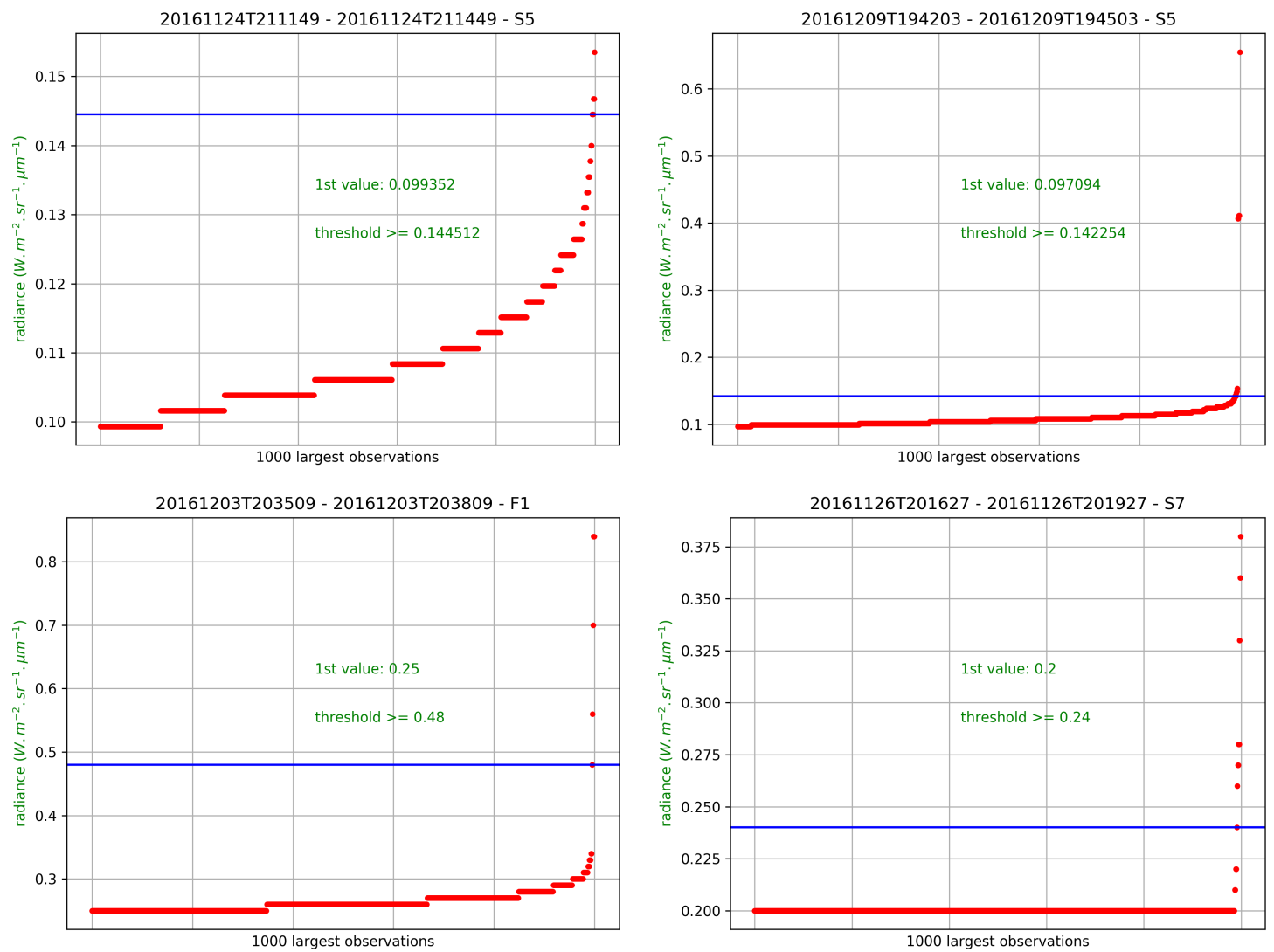

Figure 4. Four examples of thresholding for the S5 band. The horizontal line marks the threshold value. The threshold is set contextually as the lowest radiance value whose difference to the closest inferior radiance value is larger than the scale factor. 
At the end of this step, a collection of $i$ hot pixels are registered, for each of the four SWIR and MIR bands, with the following information:

- $\quad$ hot pixel location $\left(x_{i}, y_{i}\right)$ as pixel index pair

- radiance $B_{\lambda, i}$ in $\mathrm{W} \mathrm{m}^{-2} \mu \mathrm{m}^{-1} \mathrm{sr}^{-1}$

- $\quad$ area $A_{\lambda, i}$ in $\mathrm{m}^{2}$ (the the pixel length on the $x$ and $y$ axis is computed as average of the ground distance between the pixel and its direct neighbours in those axes).

\subsection{Clustering}

The clustering of contiguous hot pixels is necessary because the signal of a single hot spot may influence more than one pixel $[33,53]$. It may also be the case that a single hot spot is detected in two or more adjacent pixels $[23,37]$. Indeed, in the case of flaring a facility may comprise arrays of many flares with sizes of up to several hundred metres, while individual stations are several kilometres apart. The misregistration between SLSTR channels is not an issue here because the IR bands are treated independently up to the step right before the characterisation (see Section 3.6).

A cluster is defined as a set of hot pixels which are adjacent spacially. A cluster may comprise only one pixel if none of its adjacent pixels are hot.

A background area is defined as extending two pixels beyond the cluster's limits in any direction, including diagonally and excluding the cluster of hot pixel(s) itself . For each single pixel $i$ of the $n$ cluster's pixels, the radiance $B_{\lambda, i}$ and area $A_{\lambda, i}$ are registered. Likewise, for each single pixel $j$ of the $m$ background pixels, $B_{\lambda, j}$ and $A_{\lambda, j}$ are registered.

For each cluster, the following quantities are then computed: the average radiance and its standard deviation in $\mathrm{W} \mathrm{m}^{-2} \mu \mathrm{m}^{-1} \mathrm{sr}^{-1}$, the average background radiance and its standard deviation in $\mathrm{W} \mathrm{m}^{-2} \mu \mathrm{m}^{-1} \mathrm{sr}^{-1}$, the cluster area in $\mathrm{m}^{2}$, its $x$-position as across-track index and $y$-position as along-track index, and the number of cloud-flagged pixels (using the standard SLSTR cloud product) for both the cluster and the background.

\subsection{Misregistration Characterisation}

A hot event at temperatures typical of a gas flare, a steel mill or an iron smelter, will produce a local maximum in the SWIR and MIR channels (see Figure 2), which will be translated into a cluster in those bands. The MIR fire channels S7/F1 of SLSTR have been designed with a different footprint size and position than the corresponding SWIR channels. Because of these differences the clusters in the different bands cannot be spatially superimposed.

We determine the misregistration of channels S6, S7 and F1 relative to channel S5 by assuming that the majority of hot spots are isolated point sources: For each hot spot cluster in S6, S7 and F1, taken from a random set of 500 SLSTR scenes, the closest S5 cluster is found. For each pair, the distances of the cluster centres in along-track and across-track directions are calculated in coordinates of product image grid indeces. These distances are plotted over the across-track pixel position in Figure 5.

A systematic dependency on the across-track position is obvious in several of the plots. We, therefore, fit parabolas to the data. They represent our best estimate of the misregistration between S5 and S6 resp. S7 resp. F1. The fitted parameters are given in Figure 5. To determine confidence intervals for the misregistration estimates, the fitted parabolas are shifted vertically such that $10 \%$ of the data points are below resp. above. 


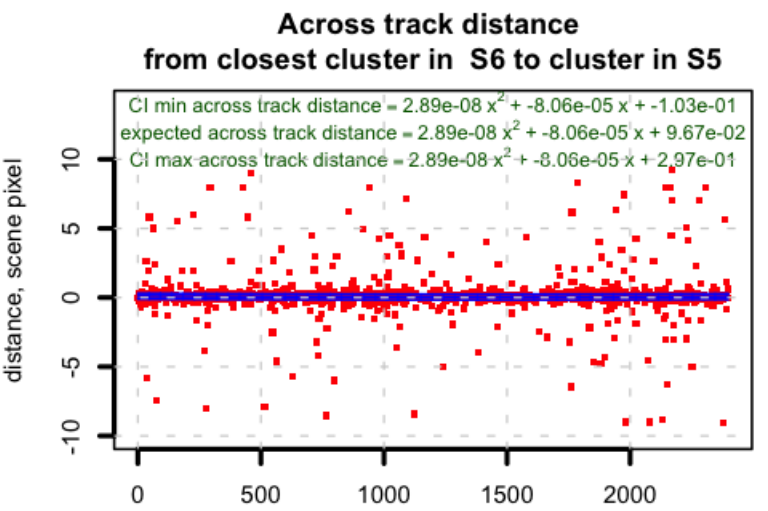

S5 position (across track index, scene pixel)

Across track distance from closest cluster in $\mathbf{S 7}$ to cluster in S5

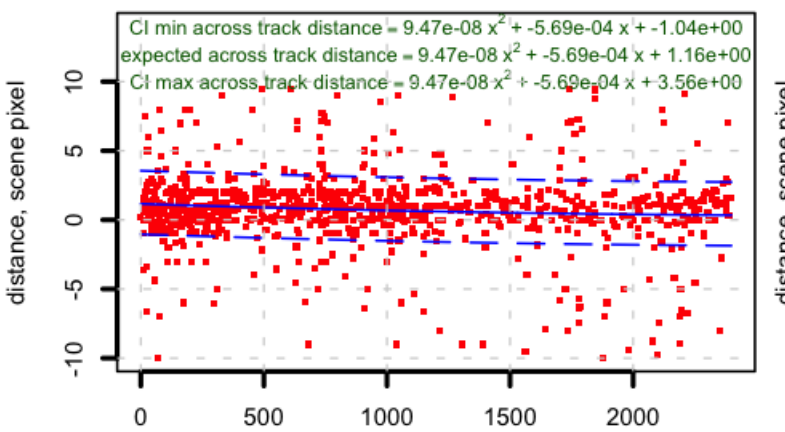

S5 position (across track index, scene pixel)

Across track distance from closest cluster in $\mathrm{F} 1$ to cluster in S5

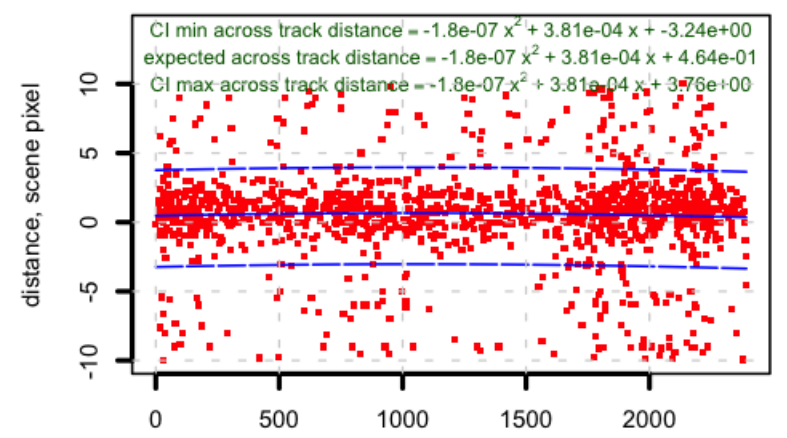

S5 position (across track index, scene pixel)

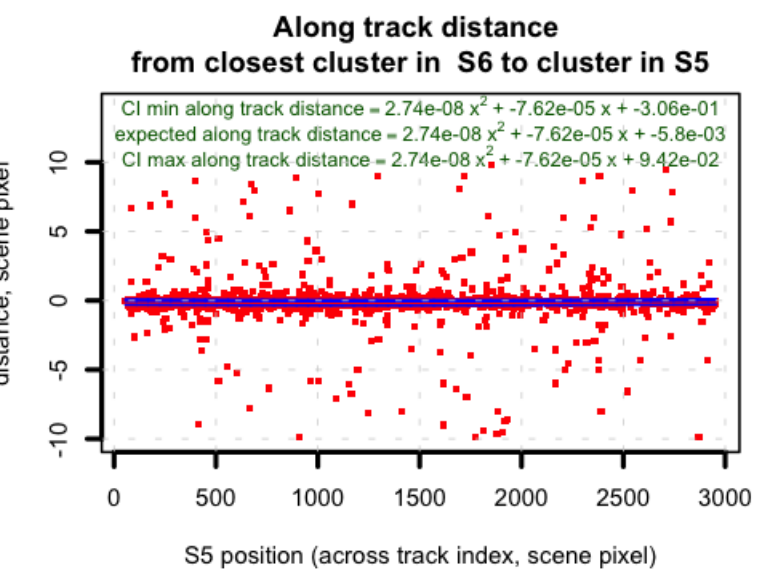

Along track distance

from closest cluster in S7 to cluster in S5

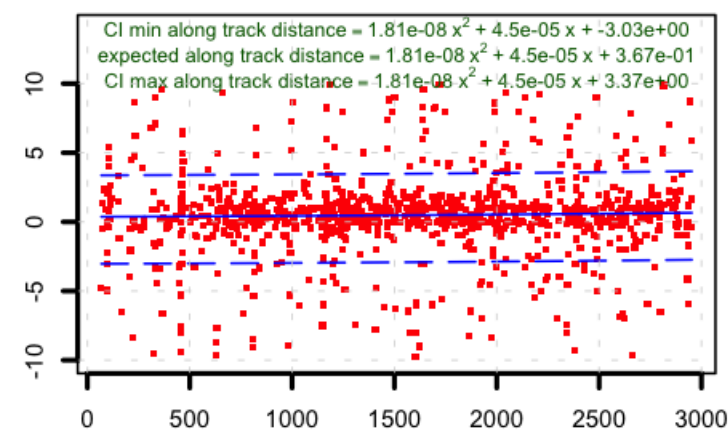

S5 position (across track index, scene pixel)

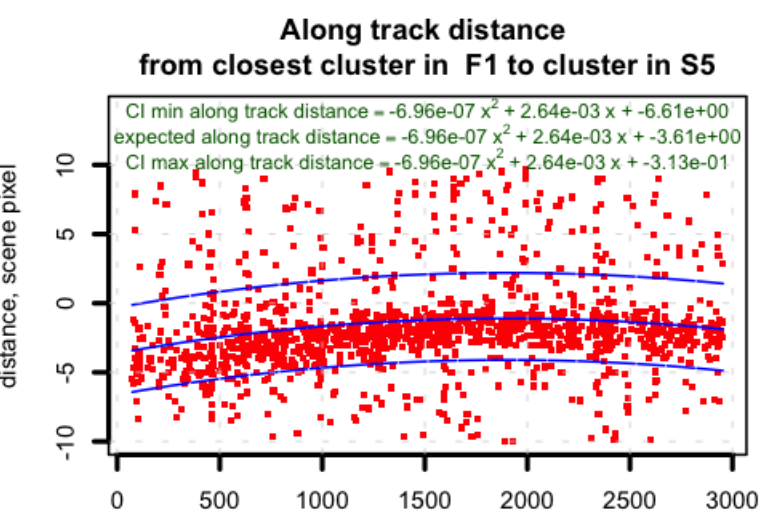

S5 position (across track index, scene pixel)

Figure 5. Parameterizations of the distances between a cluster in S5 and the closest cluster in S6, S7 and F1 as a function of the scan index. The solid line shows the best fit (second order polynomial). The dashed lines are parallel to the best fit so that $10 \%$ of the points are above resp. below. They represent the confidence interval.

\subsection{Misregistration Correction: Building Multi-Band Clusters}

Multi-band clusters $C^{\text {hotspot }}$ are subsequently constructed. They consist of the single-band clusters $C_{\lambda}$ with $\lambda$ in S5, S6, S7 and F1 that observe the same hot source. The SWIR cluster $C_{S 5}$ is used as reference. Then those clusters from the remaining bands $\left(C_{\lambda}\right.$ with $\lambda$ in S6, S7 and F1) that are closest to after correction of the misregistration are added. In doing so, only clusters in the confidence intervals are considered:

$$
\min \left\{d \mid\left(x_{\lambda}^{\min } \leq\left|x_{S 5}-x_{\lambda}\right| \leq x_{\lambda}^{\max } \wedge y_{\lambda}^{\min } \leq\left|y_{S 5}-y_{\lambda}\right| \leq y_{\lambda}^{\text {max }}\right)\right\} \rightarrow C_{\lambda}^{\text {hotspot }}=C_{\lambda}
$$


where

$C_{\lambda}$ is any of the $\lambda$-band clusters ( $\lambda$ in S6, S7 and F1),

$C_{\lambda}^{\text {hotspot }}$ is the $\lambda$-band cluster within the multi-band cluster $C^{\text {hotspot }}(\lambda$ in S6, S7 and F1),

$d=\left(\left(x_{\lambda}-x_{\lambda}^{a v g}\right)^{2}+\left(y_{\lambda}-y_{\lambda}^{a v g}\right)^{2}\right)^{\frac{1}{2}}$ is the distance between $C_{\lambda}$ and the parameterised misregistration position for the band $\lambda$,

$x_{S 5}$ and $y_{S 5}$ are the across track and along track position of the S5 reference cluster $C_{S 5}^{\text {hotspot }}$,

$x_{\lambda}$ and $y_{\lambda}$ are the across track and along track position of $C_{\lambda}$,

$x_{\lambda}^{a v g}, x_{\lambda}^{m i n}$ and $x_{\lambda}^{m a x}$ are the average, minimum and maximum distances in the across track axis given by the misregistration parameterisation as a function of the reference cluster across track position $x_{S 5}$, $y_{\lambda}^{a v g}, y_{\lambda}^{\min }$ and $y_{\lambda}^{\max }$ are the average, minimum and maximum distances in the along track axis given by the misregistration parameterisation as a function of the reference cluster across track position $y_{S 5}$.

For the TIR bands S8, S9 and F2, the flaring high-temperature event is not expected to impact the radiance (Figure 2). The average radiance for each TIR band 2 pixels around the reference S5 cluster position is then associated to the multi-band cluster.

\subsection{Radiance Corrections}

The SWIR radiances in S5 and S6 exhibit a systematic overestimation of 11 and 20\%, respectively [54]. Following recommendations by ESA, all values in the SWIR bands were corrected accordingly. This correction needs to be verified and possibly updated for future versions of SLSTR products.

After building the multi-band clusters, the MIR S7 channel is checked for saturation. If the S7 radiance is above the upper limit of the linearity range $\left(0.56 \mathrm{~W} \mathrm{~m}^{-2} \mu \mathrm{m}^{-1} \mathrm{sr}^{-1}\right.$, corresponding to a brightness temperature of $306 \mathrm{~K}$ ) in any of the hot pixels within the cluster, then it is discarded. If the S7 cluster is discarded or not present, the F1 cluster is used. The F1 band is a fire dedicated channel of SLSTR which measures at the same wavelength as the S7 channel, but with a larger dynamic range and lower sensitivity. Only F1 clusters where all of the pixels have a brightness temperature within the range $300-480 \mathrm{~K}$ are considered, as this is the range where the Level 1 quantification is accurate.

\subsection{Super Cluster Definition}

The areas of the individual clusters in the SWIR and MIR bands within a multi-band cluster may vary. To overcome this, hypothetical super clusters, with perfect coregistration and identical footprint areas in all bands, are built. The largest of the individual band clusters' areas $A_{\lambda}$ is chosen as area $A_{\text {cluster }}$ of the super cluster (Figure 6). 


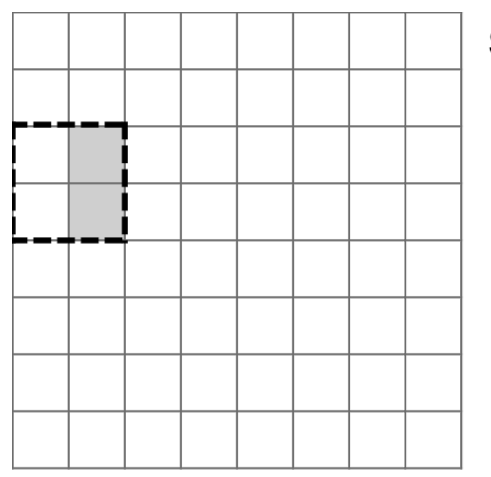

\section{S5 grid}
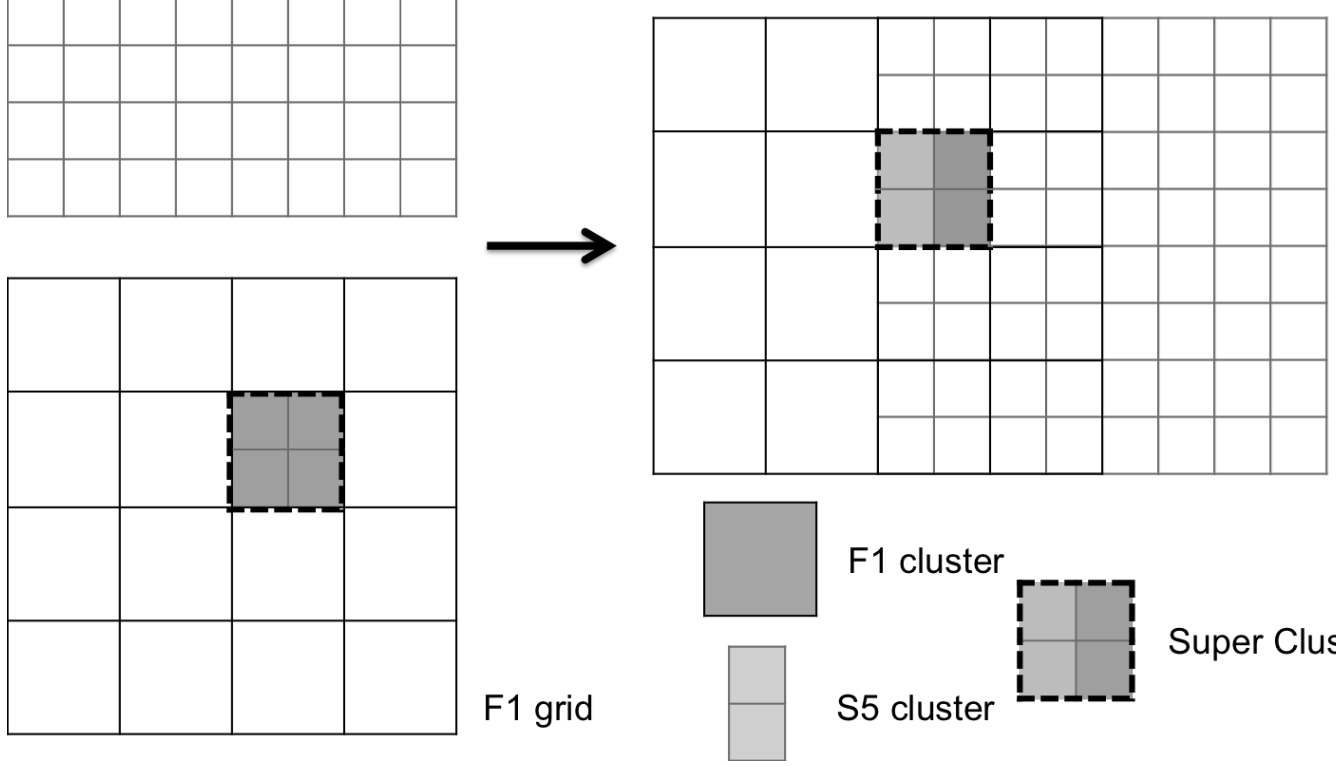

\section{F1 cluster}

S5 cluster

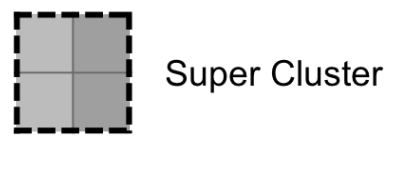

Figure 6. Super cluster creation.

For each band's cluster $C_{\lambda}^{\text {hotspot }}$ within a multi-band cluster $C^{\text {hotspot }}$, the observed cluster radiance $B_{\lambda}^{o b s}$ is calculated as area-weighted average of the observed radiances of the cluster and the background:

$$
B_{\lambda}^{\text {obs }}=\frac{B_{\lambda} \times A_{\lambda}+B_{\lambda}^{b g} \times\left(A_{\text {cluster }}-A_{\lambda}\right)}{A_{\text {cluster }}}
$$

It is assumed that the background radiance $B_{\lambda}^{b g}$ is constant in the vicinity of the cluster. For the TIR bands (S8, S9 and F2) the weighting is not necessary as the hot spot signal is not expected to be distinguishable from the background in that spectral region and the average radiance of background and cluster, is used.

\subsection{Planck Curve Fitting}

To determine the temperature and the area of the flaring event, the sum of two Planck curves is fitted to the radiance data of the multiband cluster, as established by Elvidge et al. [19] (Figure 7). The two Planck curves represent the two contributors for the IR radiance measured by the sensor at night, i.e., the flaring event and the background, each weighted by its respective relative area:

$$
\begin{aligned}
B_{\lambda}^{\text {obs }} & \stackrel{!}{=} B\left(\lambda, T_{\text {bg }}\right) \times\left(1-\frac{A_{\text {hotspot }}}{A_{\text {cluster }}}\right)+B\left(\lambda, T_{\text {hotspot }}\right) \times \frac{A_{\text {hotspot }}}{A_{\text {cluster }}} \\
B(\lambda, T) & =\frac{2 h c^{2}}{\lambda^{5}} \frac{1}{e^{\frac{h c}{\lambda k T}-1}}
\end{aligned}
$$

where $B\left(\lambda, T_{\text {hotspot }}\right)$ and $B\left(\lambda, T_{b g}\right)$ are the modelled hot spot and background radiance, respectively, according to Planck's law. $A_{\text {hotspot }}$ is the modelled flame area $\left[\mathrm{m}^{2}\right]$.

The $B_{\lambda}^{\text {obs }}$ values , obtained from the Super Cluster (see Section 3.6), are approximated by fitting the parameters $T_{b g}, T_{\text {hotspot }}$ and $A_{\text {hotspot }}$ via the least squares methodology. The standard deviation 
of the background radiances $\sigma_{\lambda}^{b g}$ is used in the fitting as standard deviation of the cluster radiances. The algorithm computes uncertainties for both the temperature and the area.

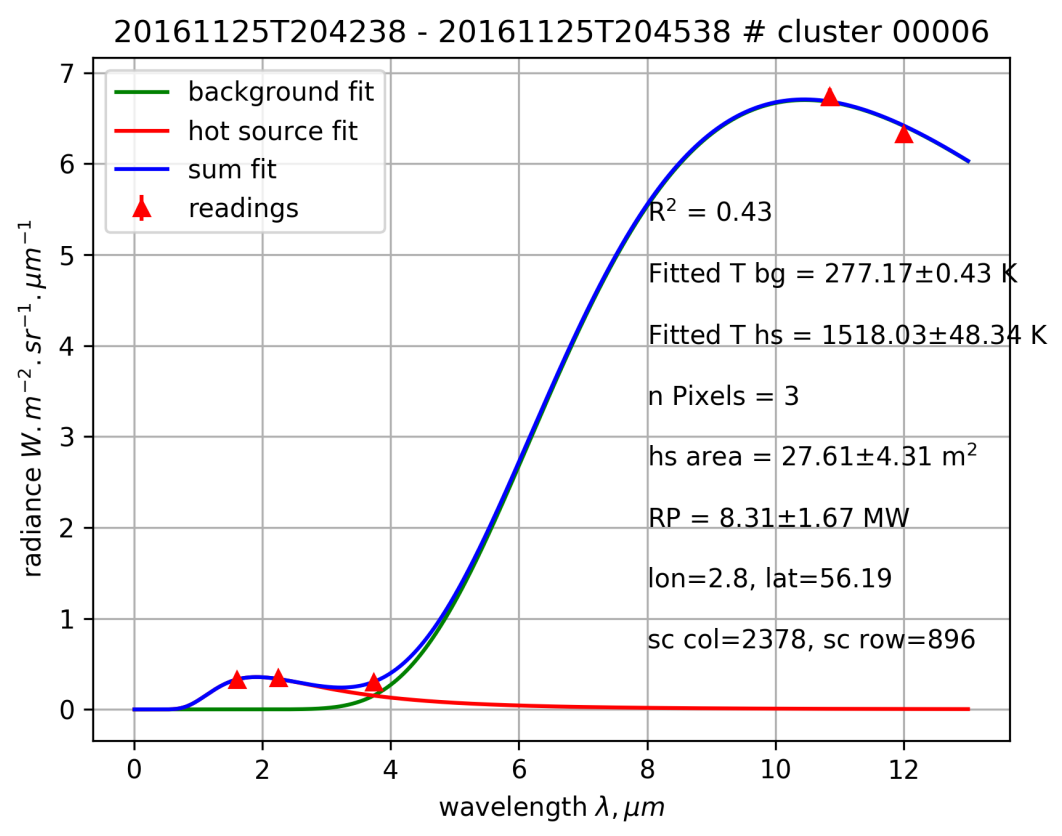

Figure 7. An example of the temperature and area retrieval by dual Planck curve fitting. More examples can be found in the Supplementary Materials.

\subsection{Radiative Power}

The radiative power (RP) of the hot source may then be computed using the Stefan-Boltzmann equation and assuming a perfect emissivity (in $\mathrm{W}$ ):

$$
R P_{\text {hotspot }}=A_{\text {hotspot }} \times \sigma_{S B} \times T_{\text {hotspot }}^{4}
$$

where $\sigma_{S B}$ is the Stefan-Boltzmann constant $\left(5.670373 \times 10^{-8} \mathrm{~W} \mathrm{~m}^{-2} \mathrm{~K}^{-4}\right)$. The respective uncertainty is computed by propagation of errors.

Elvidge et al. [19] used the VIIRS M10 band as a primary band for the detection of gas flares and found that "there is a strongly coherent linear relationship between top of the atmosphere and atmospherically corrected RH [radiant heat]". The authors thus conducted their work with the uncorrected TOA radiances. Since the S5 band of SLSTR is within the same clear atmospheric window, the same choice was made for the present work.

\section{Results}

\subsection{Regional Study: 4 Flaring Regions}

The described algorithm was applied to observations in the four regions of West Africa, the North sea, the Caspian sea and the Persian gulf, cf. Table 2.

\subsubsection{Detection Thresholds}

Figure 8 shows the relationship between the retrieved temperature and area of hot spots detected by SLSTR and compares it with the noise-equivalent radiance levels for the detection bands (S5, S6, S7 and F1) and with the limit of detection derived for VIIRS Nightfire [36]. The cloud of points generally follows the M10 detection limit derived by Elvidge et al. [36], but also expands slightly to lower 
threshold values in the regions of typical industrial temperatures (around $1000 \mathrm{~K}$ ) and gas flaring (1500-2000 K).

Hot spots detected in the S5 channel only (grey crosses in Figure 8) represent $5 \%$ of all the hot spots within the study regions. They exhibit temperatures in the lowest end (600-1000 K) of the range of retrieved temperatures and areas in the upper end $\left(10^{2}-10^{5}\right)$ of the range of retrieved areas. These values are highly uncertain because only one constraint exists in the SWIR and MIR range so that the TIR radiances are expected to be overfitted. The retrievals are thus treated as "low-accuracy" (see Section 4.1.4). Clusters detected in the MIR (green and blue crosses in Figure 8) represent $28 \%$ of all the hot spots within the study regions (3\% S5 and MIR and 25\% in S5, S6 and MIR). The lower limit of the cloud follows an isoradiance line that represents a larger radiance value (approximately $5 \mathrm{~W} \mathrm{~m}^{-2} \mathrm{sr}^{-1} \mu^{-1}$ ) than the noise-equivalent for S7 or F1 from the instruments specifications. We attribute this to the larger variability of the background in the MIR. Hot spots detected in both SWIR channels (S5 and S6) but not in the MIR channels (pink points in Figure 8) make up the most of the detections (67\%). Hot spots in the region below the M10 limit of detection (blue dashed line) as derived by Elvidge et al. [36] were detected in both SWIR channels. They are mostly in the expected range for gas flares (1300-2000 K [19]). This suggest some capability, thanks to the availability of both SWIR channels, to detect smaller gas flares than those detected by VIIRS. SLSTR can also characterise the smaller gas flares more effectively using the Planck curve fitting method.

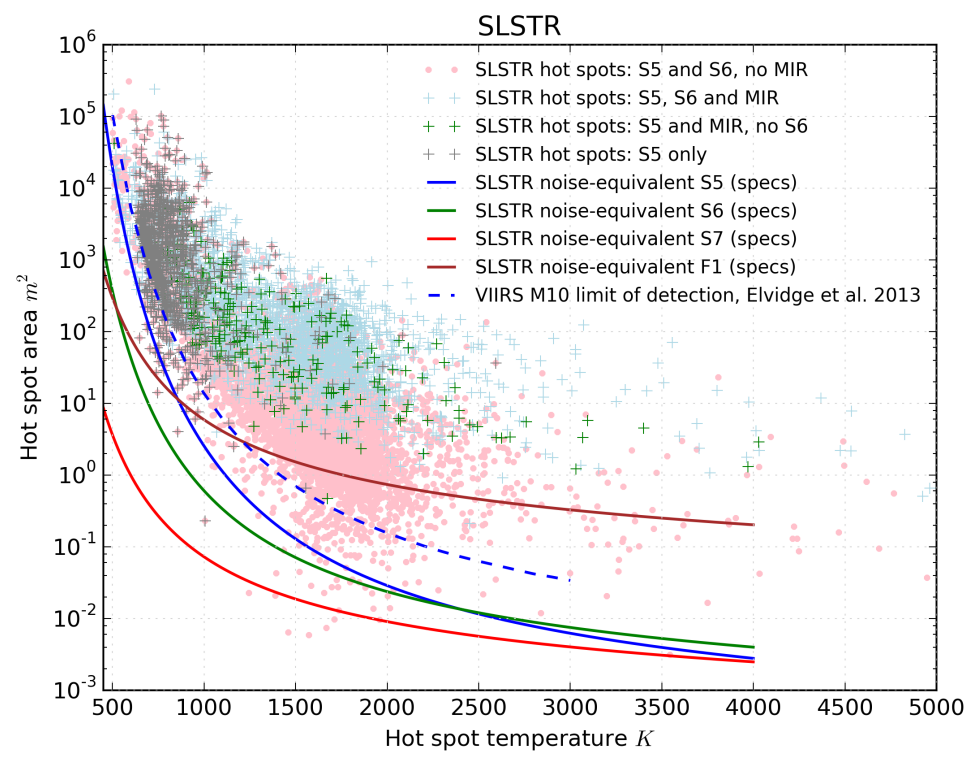

Figure 8. Relationship between the temperatures and areas of all retrieved hot spots. The solid lines represent the noise-equivalent radiance levels for SLSTR SWIR and MIR channels computed from the instruments specifications (see Figure 3). The dashed line represents the limit of detection for the VIIRS M10 channel derived by Elvidge et al. [36].

\subsubsection{Temperature and Area Retrievals}

Figure 9 shows the hot spot detections of SLSTR with temperatures in the range [500 K, $5000 \mathrm{~K}$, which we consider to relate to actual hot spots on the ground. The methodology identifies hot spots in regions where flaring is known to occur (e.g., the North Sea oil fields, the mouths of the Congo and Niger rivers, the Persian Gulf and the Tigris and Euphrates rivers valleys). Figure 10 shows the temperature distributions in nine specific areas: four areas with know gas flaring, one area with biomass burning and four areas without any known hot objects. Hot spots detected offshore where no oil extraction activities are present show a clearly lower temperatures than for the other studyregions. Hot spots were also detected in the plateau of central Angola and 
the Southern D. R. Congo. The intermediate temperatures retrieved in those regions indicate the presence of biomass burning. Observing fire temperature on a global scale, even only at night-time, is complementary to the widely used burnt area and fire radiative power observations and has great potential for reducing errors in the current vegetation fire emission datasets.

Hot spot characteristics evaluated from space could be dependent on the viewing angle. This was shown to be relevant for VIIRS [19]. However,

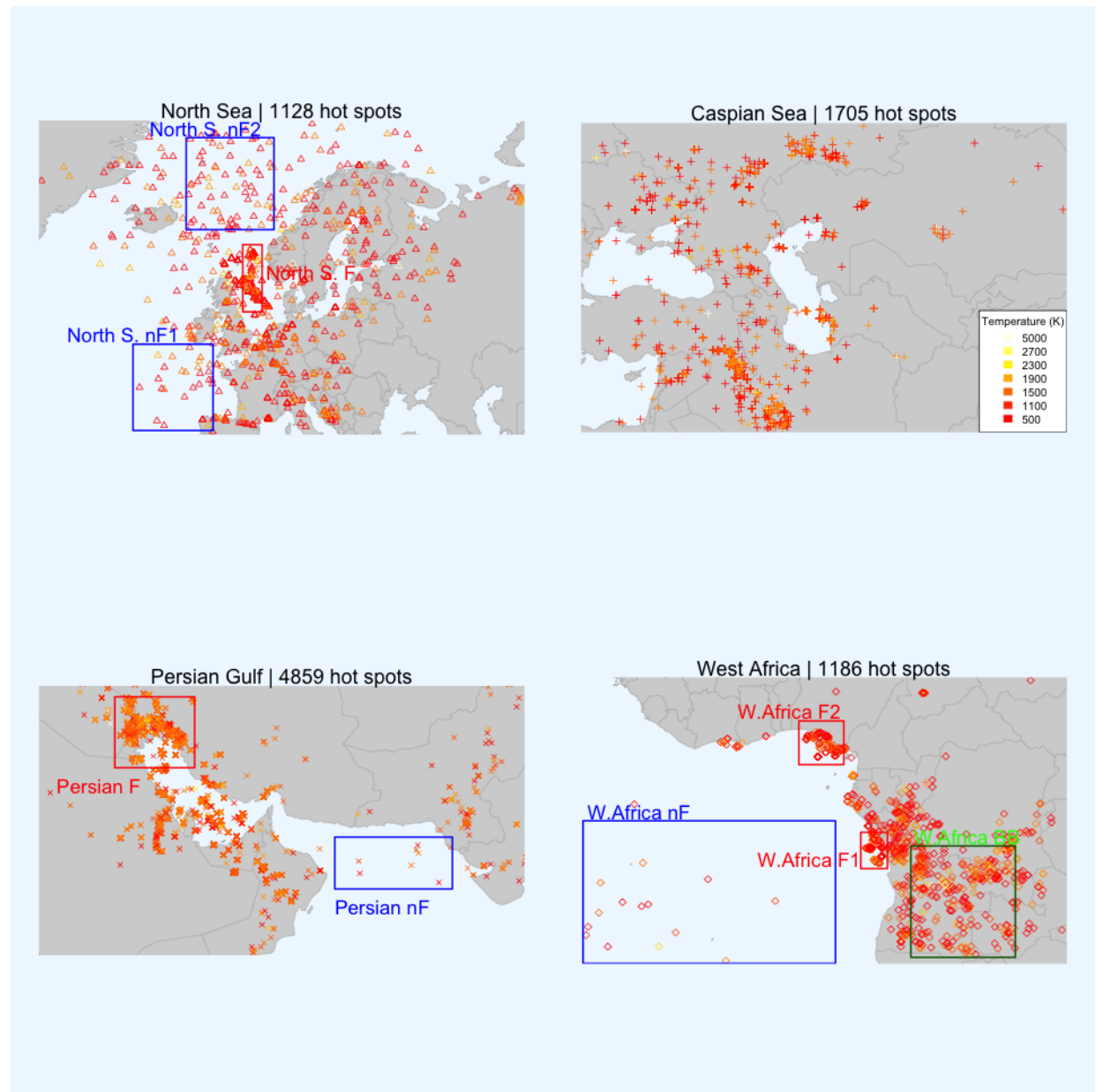

Figure 9. Maps of the hot spots within the test regions. The rectangles represent the 9 study areas (red for flaring, green for biomass burning, blue for non-flaring).

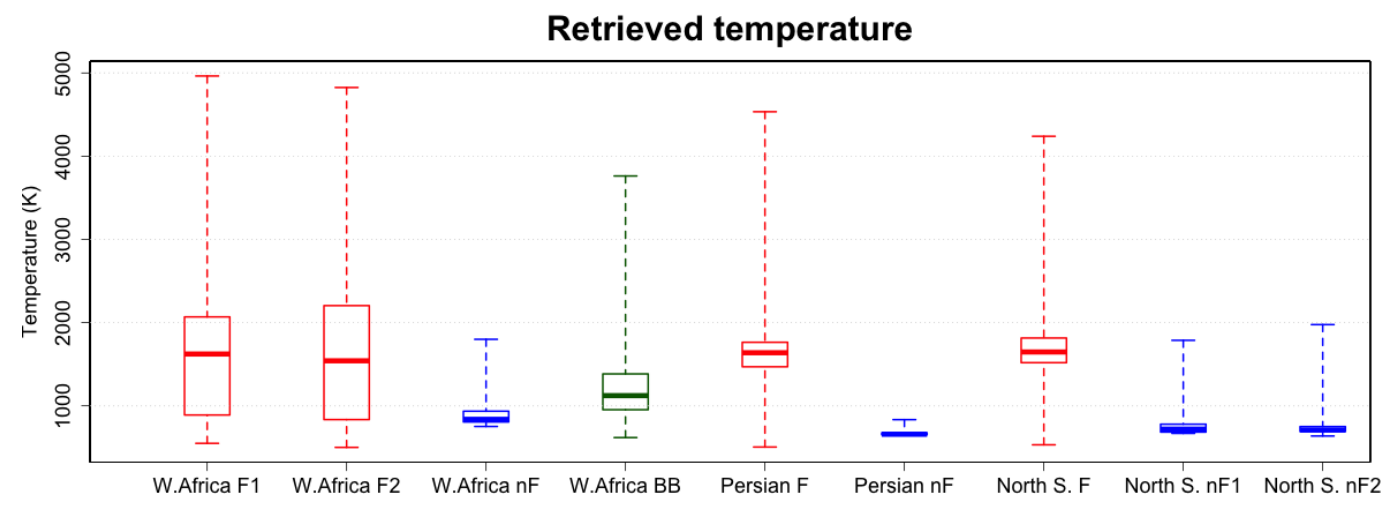

Figure 10. Temperature retrievals distribution for the hot spots within each study area defined in Figure 9. 
SLSTR has a narrower range of viewing angles and the effect is not expected to be as pronounced. Since we fit an unconstrained Planck curve, this effect would be noticed in both the retrieved temperature and area. We therefore present the retrieved hot spot radiative power variation dependending on the across track index in Figure 11. There is no apparent effect.

\section{Retrieved radiative power (MW) North Sea}

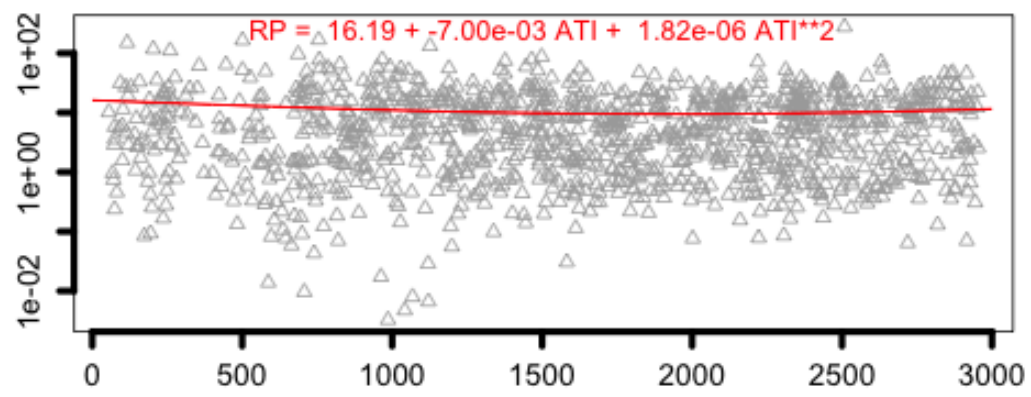

Caspian Sea
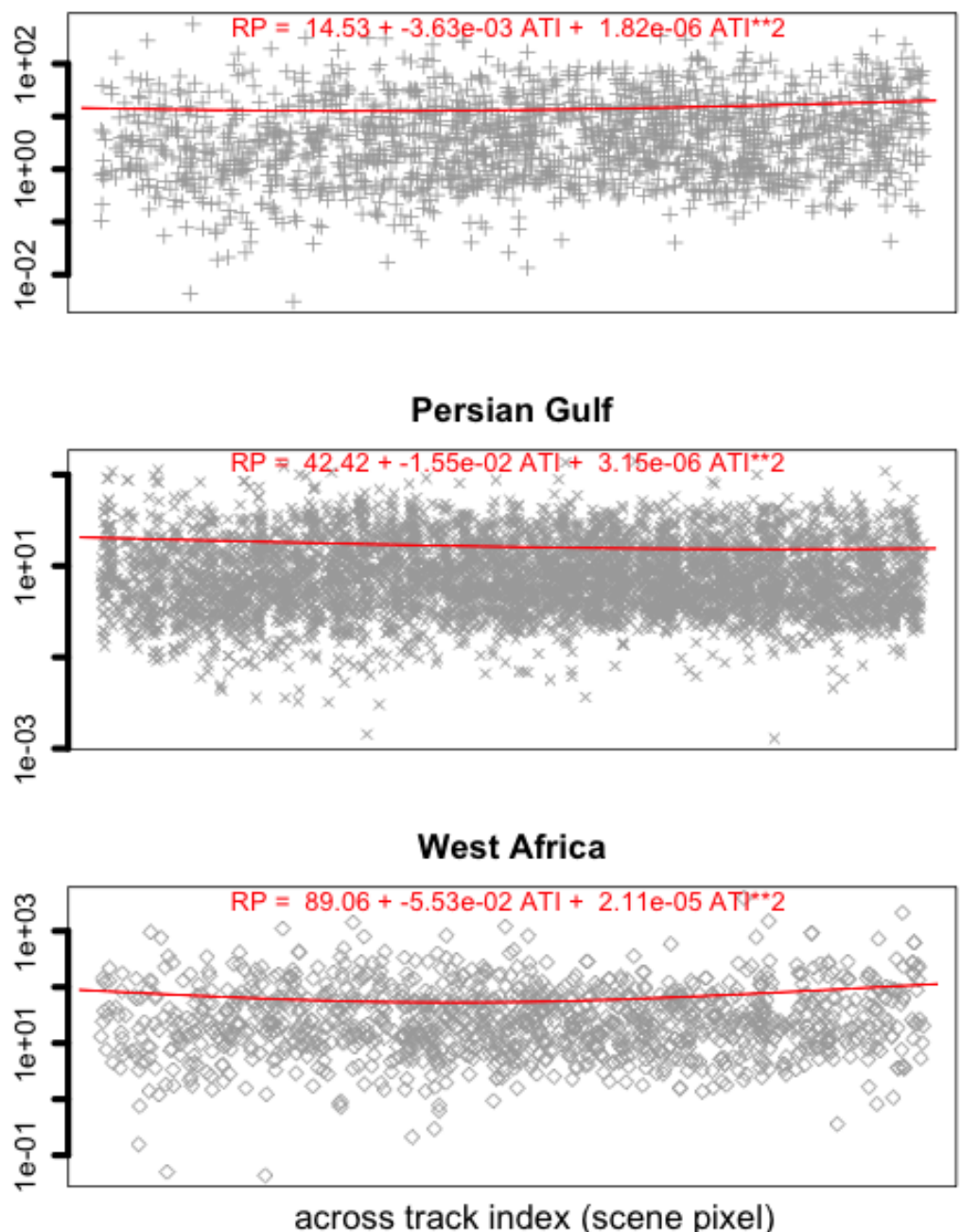

Figure 11. Retrieved radiative power for hot spots as a function of the across track index (ATI).

\subsubsection{Persistence}

Hot or bright events that can be observed from space in the IR part of the spectrum at night include gas flares, wildfires, auroras, industry (e.g., steel mills) and volcanoes [34,36]. Noise and an increased exposition of the sensor to radiation due to the South Atlantic Anomaly may also generate 
spurious hot spots $[19,34]$. It is possible to discriminate between these events based on retrieved characteristics, such as the temperature $[19,55]$. In the present work, we opt for an analysis of the persistence of the signal at the location of a given hot spot as it has been used previously to filter out noise and ephemeral phenomena [19,34].

We base the definition of our criterion on the work of Casadio et al. [34], who used a threshold of at least 4 detections a year for (A)ATSR, the heritage instrument of SLSTR. Since the swath of (A)ATSR is roughly one third of SLSTR's, the criterion would correspond to 12 times a year for SLSTR. The sampling period is roughly 2 months, corresponding to 2 observations within that period. This was raised to 3 in order to filter out noise.

Although not suitable for a thorough analysis due to the short sampling period, the persistent hot spots (at least 3 detections within a spatial accuracy of \pm 0.02 degrees in longitude and latitude over the sampling period) mainly correspond to locations within known flaring regions (see Figure 12). In future works where this methodology will be used on data from longer periods, this threshold might need to be raised or otherwise adapted. For known interferences, persistent or semi-persistent hot sources such as volcanoes, the use of a mask will also be useful.

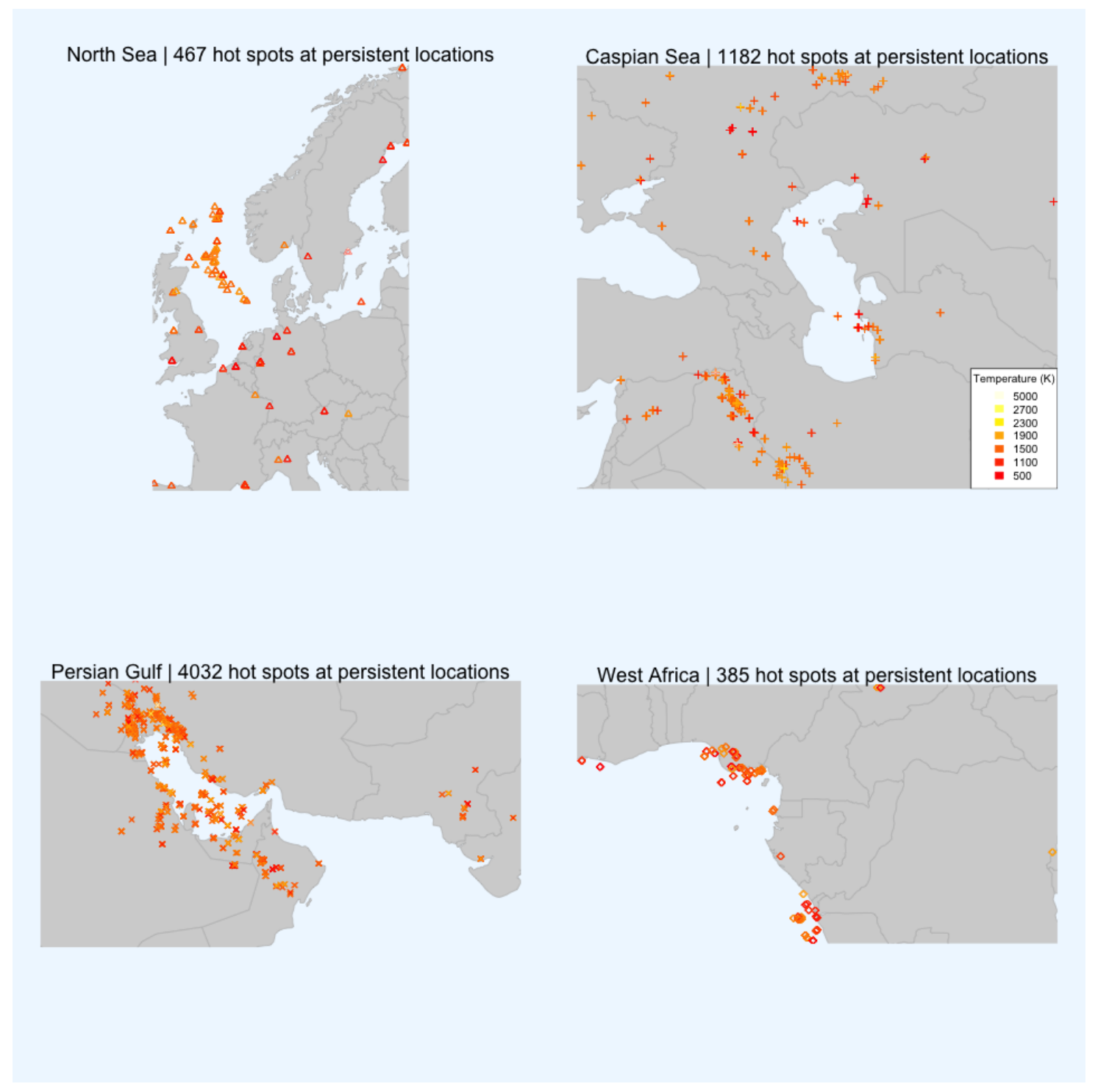

Figure 12. Maps of the persistent hot spots. 
The persistent locations thus derived were compared with high resolution imagery (Google Earth, for the Caspian Sea test region) in order to check for the existence of a hot spot: at 96 (65\%) of the 148 persistent hot spot locations a gas flare was visible, $34(23 \%)$ locations were offshore or onshore but lacking sufficient resolution, $12(8 \%)$ were onshore locations without an industrial area nor a visible gas flare nearby and $6(4 \%)$ were at an industrial site without a visible flare.

\subsubsection{Selection of Persistent Hot Spots and Radiative Power Computations}

To filter low-quality determinations, cloud cover and overfitting were considered.

Clouds may interfere with the amount of radiation measured by the SLSTR instrument, in turn interfering with the temperature, area and radiative power retrievals. However, simply discarding cloudy pixels could incur a large omission error since pixels containing gas flares are frequently marked as clouds, namely as isolated cloudy patches (e.g., for the VIIRS instrument [19]). For this reason, we analyse the cloudiness of the background, as defined in Section 3.2, and discard only observations with less than 3 cloud-free background pixels.

To avoid too much dependence on the TIR channels, which are not affected by small hot sources with the temperature of gas flares, we discard persistent hot spots for which no clusters were detected in S6, S7 and F1. In the work of Elvidge et al. [19], signals detected in the $1.6 \mu \mathrm{m}$ channel only are not quantitatively evaluated and information from nearby hot spots is used. Although we compute the hot spot temperature and fraction area and the background temperature with the dual Planck curve fitting (Section 3.7) using data from the super cluster (S5 and TIR channel, Section 3.6), we opt to discard those results (clustered in a low temperature/large area region, Figure 8) and to not assume any characteristics for that particular detection. Since these detections are only $5 \%$ of the total hot spot persistent detections, we assume that they do not significantly influence hot spots characterization within the study regions.

Figure 13 shows the distributions of the retrieved temperature, area and radiative power for detections that have been filtered with the persistence, cloud cover and S6/S7/F7 availability criteria described above. We will label these "high-accuracy persistent" below. A range of temperatures around $1800 \mathrm{~K}$ can be considered as characteristic for flaring $[19,36]$, and the distributions of the high-accuracy persistent hot spots fall mostly within the expected range for gas flares, but observations in the 500-1500 K temperature range are also important. The retrieved temperatures show a clearly unimodal distribution approximately centered at $1600 \mathrm{~K}$ for the Persian Gulf and the Caspian Sea test regions. For the North Sea test region, the distribution is bi-modal, with modes around $1000 \mathrm{~K}$ and $1600 \mathrm{~K}$. While the latter is probably associated with gas flaring, the former is more likely associated with industry (see Figure 12, the colder persistent detections are onshore) [19]. There were very few high-accuracy persistent hot spots for the West Africa test region due to unfavourable cloud conditions. 


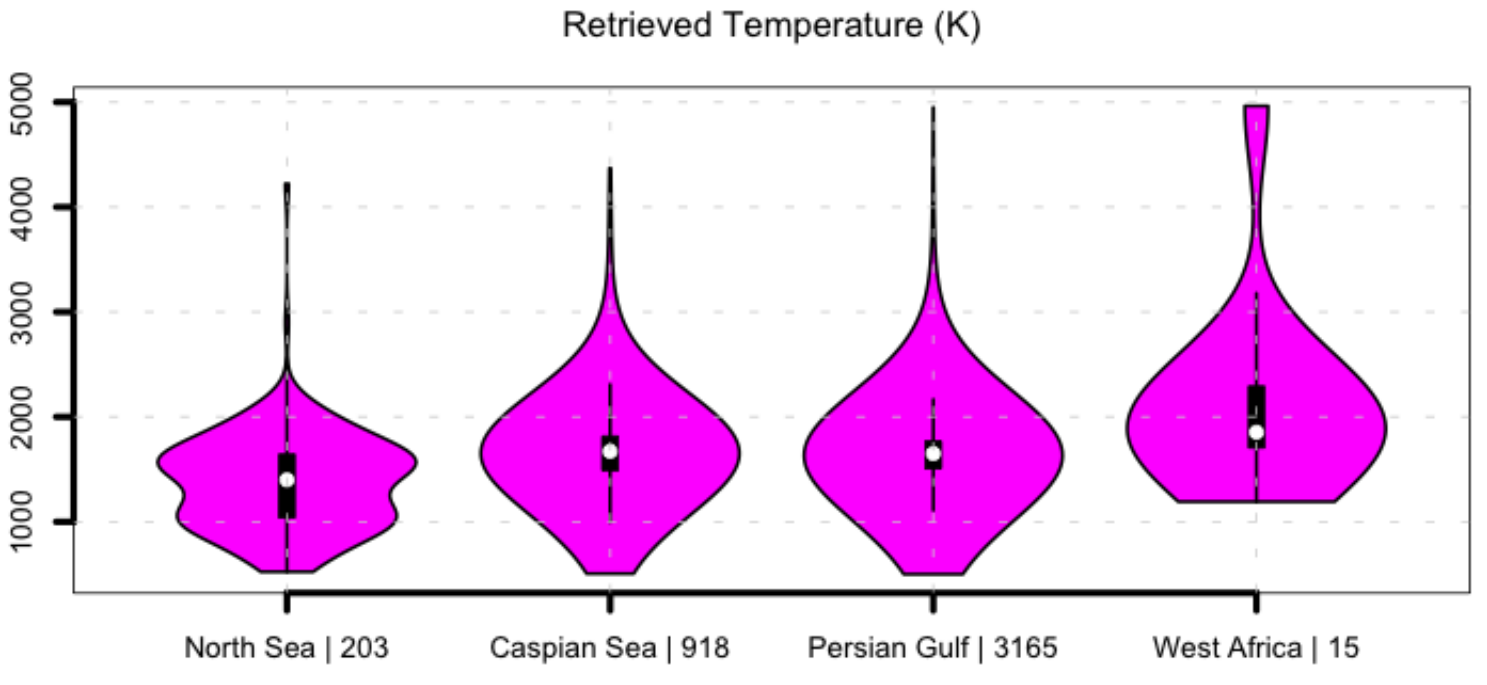

Retrieved Area $\left(\mathrm{m}^{2}\right)$

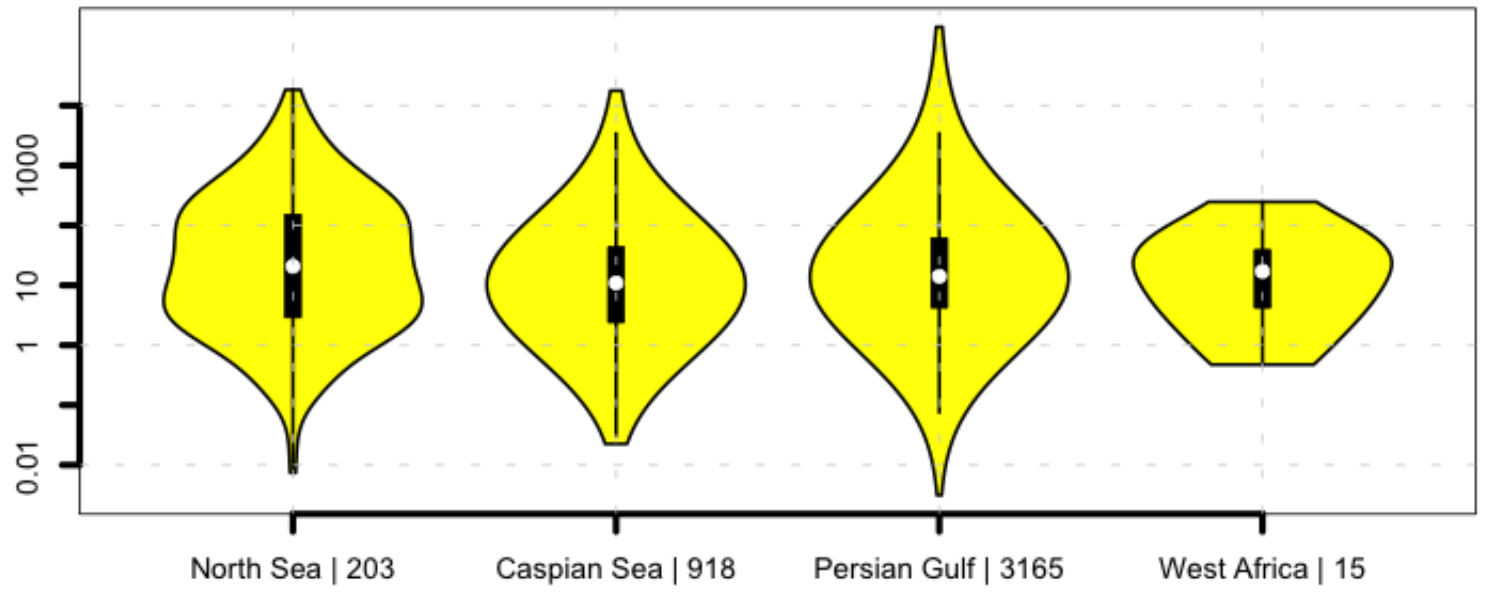

Retrieved radiative power (MW)

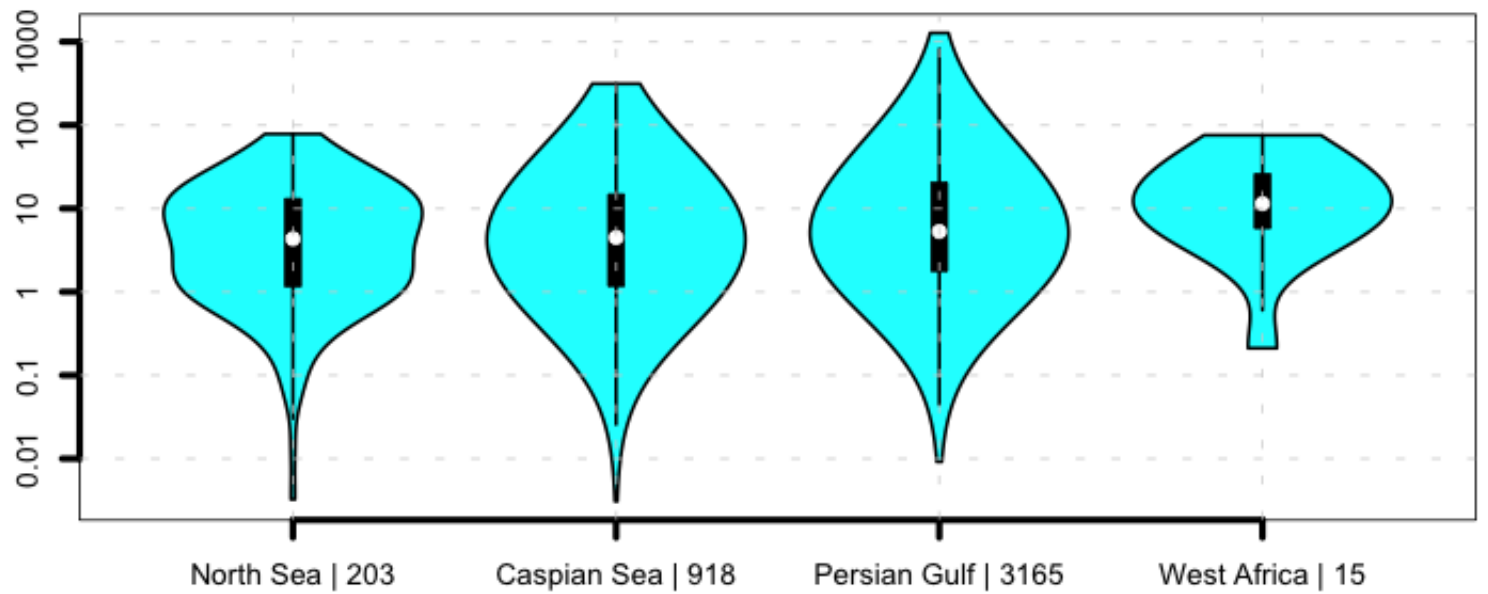

Figure 13. Violin plots for the temperature, area and the radiative power retrieval distributions of the high-accuracy persistent hot spots. The number of high-accuracy persistent hot spots is also indicated. 


\subsubsection{Comparison with VIIRS Nightfire}

The SLSTR hot spot at persistent locations were compared to the VIIRS Nightfire data for a same time period and a roughly similar area. The VIIRS Nightfire results were subject to the same spatial persistency analysis as the SLSTR data (3 times within a spatial accuracy of 0.02 degrees in longitude and latitude). VIIRS detects more gas flaring locations than SLSTR, which can be traced back to its wider swath (3040 km against $1420 \mathrm{~km})$, and thus a shorter revisit time. Another reason for the larger number of detections by VIIRS is that the Nightfire algorithm processes single pixels, selected as the local maxima of pixels above the threshold, the method here aggregates contiguous hot pixels into clusters. Despite these differences, all but one persistent locations detected by SLSTR were also detected by VIIRS (Table 3). The VIIRS Nightfire algorithm produces a slightly larger fraction of detections in the $1.6 \mu \mathrm{m}$ channel only ( $7 \%$ for Nightfire against $5 \%$ for the present work). However, when considering Nightfire detections in the $1.6 \mu \mathrm{m}$ and visible $(0.5-0.9 \mu \mathrm{m}$, Day-Night Band, DNB) channels, the fraction is very important: $55 \%$, as is the fraction of SLSTR hot spots detected in both SWIR channels only (67\%). The MIR channels, both of VIIRS and SLSTR, produce less detections than the SWIR channels. We interprete this as a larger variability of the background in the MIR region, as well as a lower sensitivity to high temperature sources (Figure 2).

The clustering of contiguous hot pixels used in the present method also explains why the VIIRS Nightfire temperature retrievals tend to peak at higher values than the SLSTR ones (Figure 14). Selecting only pixels which are local maxima, as the VIIRS Nightfire algorithm does, will produce detections with higher radiances and mostly higher temperatures will be retrieved.

Table 3. Summary of the detections based on SLSTR and spatial comparison with VIIRS Nightfire.

\begin{tabular}{lcccc}
\hline & North Sea & Caspian Sea & Persian Gulf & West Africa \\
\hline SLSTR & & & & \\
hot spots & 1128 & 1705 & 4859 & 1186 \\
persistent hot spots & 467 & 1182 & 4032 & 385 \\
high-accuracy persistent hot spots & 203 & 874 & 3096 & 15 \\
persistent locations & 72 & 148 & 359 & 57 \\
\hline persistent locations detected by VIIRS & 71 & 148 & 359 & 57 \\
\hline
\end{tabular}



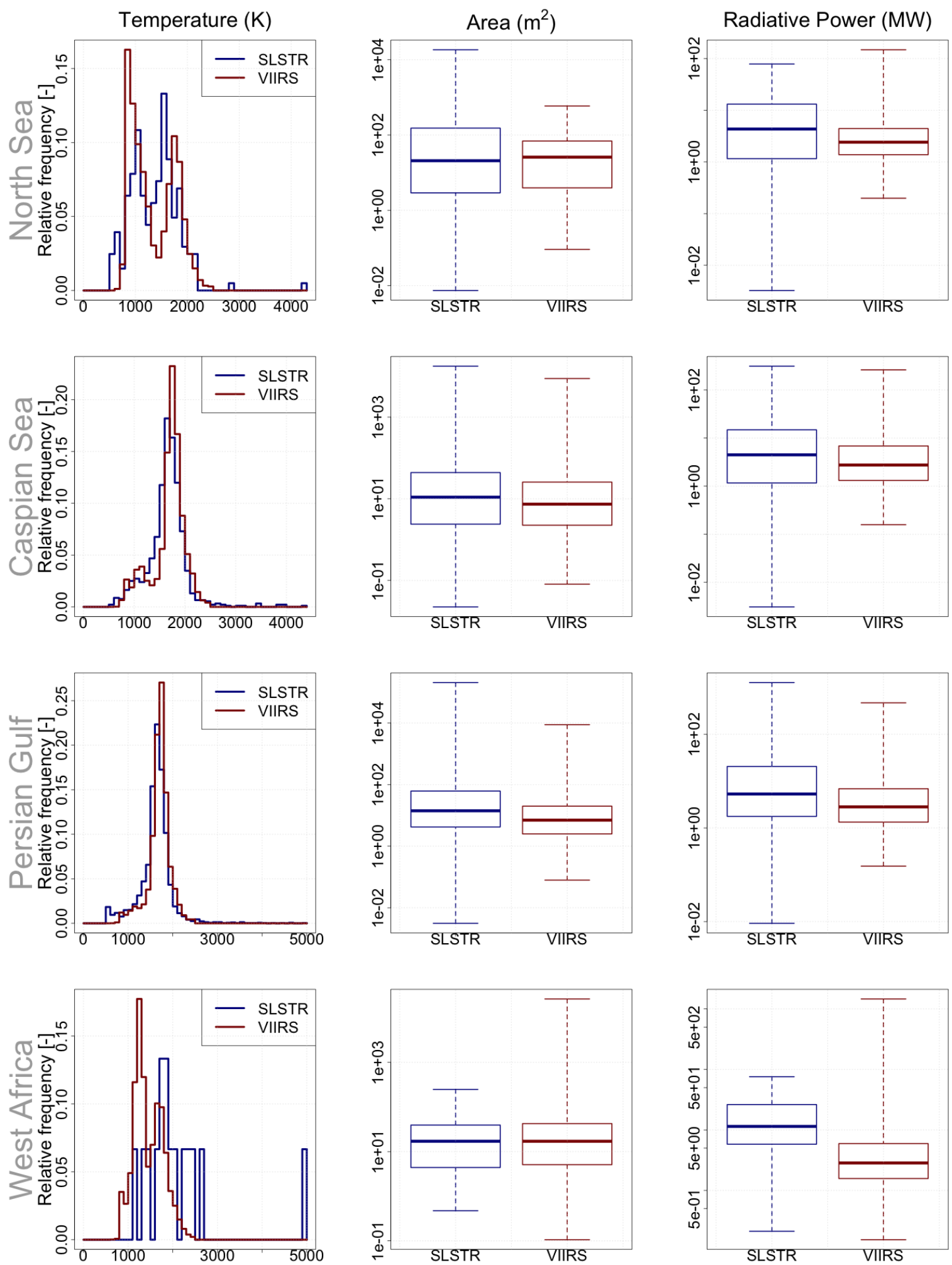

Figure 14. Comparison between temperature, area and radiative power retrieved by SLSTR and VIIRS at persistent locations.

\subsection{Single Site Study: Bovanenkovo, Yamal Peninsula}

As another test case, a flaring site in the Bovanenkovo field was observed in more detail. This analysis is performed in order to test the capabilities of the presented algorithm, not only in 
statistical terms (as conducted when comparing with VIIRS Nightfire), but also at the single site level. The Bovanenkovo field, located on the western shore of the Yamal peninsula in northern Siberia, Russia, produces natural gas and condensates. The flaring location was repeatedly observed by the sensors SLSTR, HSRS and VIIRS over a sampling period of 19 days (between 15 December 2016 and 2 December 2017), with very high temporal co-location between SLSTR and HSRS. The detections are clustered around 4 distinct locations (see Figure 15) and are summarized in Table 4.

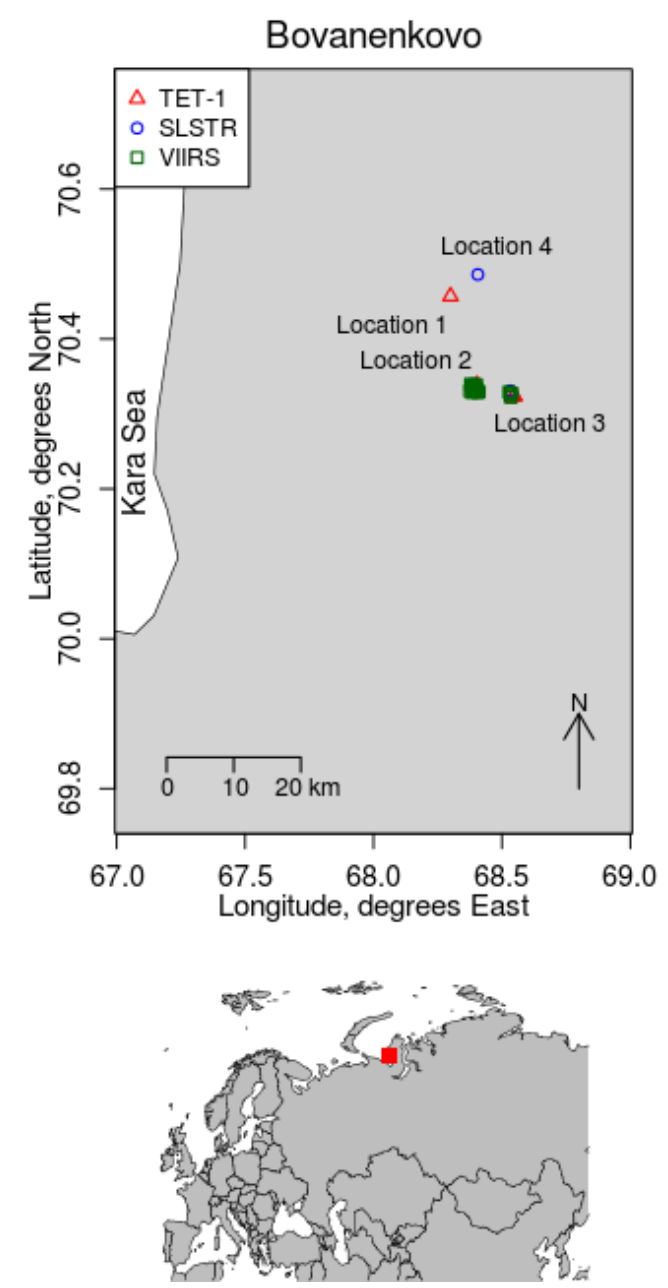

Figure 15. Location of the detections in the Bovanenkovo area between 15 December 2016 and 2 January 2017 (upper) and location of Bovanenkovo in Eurasia (lower).

Table 4. Summary of the detections at the Bovanenkovo gas and condensates field in the Yamal Peninsula, Siberia.

\begin{tabular}{ccccc}
\hline & SLSTR & HSRS & VIIRS & Total \\
\hline Location 1 & 0 & 1 & 0 & 1 \\
Location 2 & 1 & 2 & 17 & 20 \\
Location 3 & 2 & 3 & 6 & 11 \\
Location 4 & 1 & 0 & 0 & 1 \\
\hline Total & 4 & 6 & 23 & 33 \\
\hline
\end{tabular}

Due to clustering in the SLSTR and HSRS data analysis, these sensors may detect one cluster in a situation, in which the VIIRS product lists two or more flares in very close proximity. For SLSTR, the 
observing conditions were very close to twilight (the night-only mask was not considered in order to have the opportunity to observe the same flaring site by the three sensors), and thus not ideal.

Figure 16 shows the temperature, area and radiative power determinations at Locations 2 and 3 for the 3 instruments.
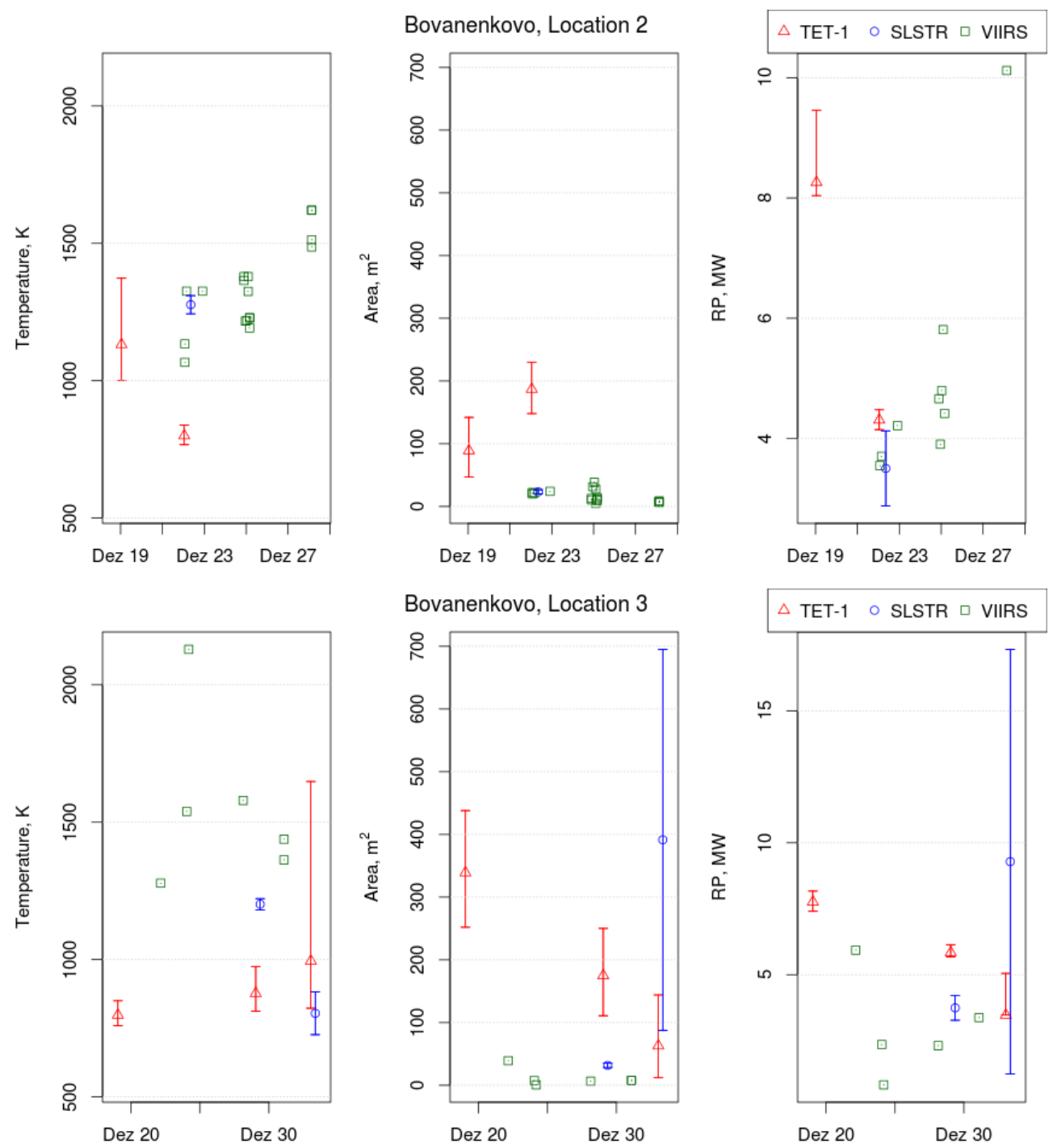

Figure 16. Temperature, area and radiative power determination for the detections at locations 2 and 3. Radiative power determinations based on VIIRS for a same overpass were added. The error bars reprent the bounds for TET-1 and the standard deviation for SLSTR.

At Location 2, the single SLSTR observation agrees well with the determinations based on VIIRS and HSRS for the temperature. At Location 3, the temperature determinations based on SLSTR are lower than those based on VIIRS but in the same range as those based on HSRS. The gas flare temperature depends on the flared gas composition and the completeness of combustion, which depends on flare design and meteorological conditions [56-59]. Thus, the flaring characteristics may vary in time. The methodological differences may also explain lower temperatures in the SLSTR product as explained above.

While the retrieved areas from TET-1 are larger than those from SLSTR, area determinations based on VIIRS and SLSTR are close for both locations except the highly uncertain SLSTR observation on 2 January 2017. The shape of the flame, and thus its area as observed by a satellite, is dependent 
on the flow rate and the meteorological conditions $[57,60]$ and therefore also variable in time as its temperature.

Despite the variability seen between sensors due to inherent variability of flares and methodological differences, the radiative power determinations, the variable to which the emissions computations are linked, compare well between sensors.

\section{Conclusions}

We have adapted the VIIRS Nightfire algorithm [19] for the detection and characterisation of persistent hot spots using the SLSTR instrument on-board the Copernicus Sentinel-3 satellite [46]. The algorithm is based on fitting Planck curves that represent the hot source and the cool background to all the available satellite observations in the short-wave, mid and thermal infrared spectral range. This approach relies on radiometrically calibrated radiance data as input.

The main difference to the original methodology is that we analyse the integrated radiances of contiguous clusters of hot pixels instead of the maximal radiances detected in the clusters. We expect this representation to be more realistic and accurate for large arrays of gas flares. The presented algorithm furthermore tolerates misregistration and variable footprint areas between different spectral channels. The misregistration itself is quantified in a post-processing step. Finally, a new hot spot detection algorithm is employed and spurious cloud masking of just the hot source is ignored.

The concept of monitoring persistent hot spots with SLSTR using the new algorithm has been tested using Sentinel-3A observations in four regions of interest: North Sea, Caspian Sea, Persian Gulf and Gulf of Guinea.

Our methodology detects persistent hot spots, including gas flaring activity, at locations coincident with oil extraction sites and comparisons to the established VIIRS Nightfire product show that the locations of the detections are largely consistent. The characterisation of the persistent hot spot in terms of temperature, area and radiative power is also similar. Thus, we conclude that night-time persistent hot spots can be monitored and characterised with the Sentinel-3 satellites. The retrieved persistent hot spot temperatures are slightly lower, areas are slightly larger and radiative power is slightly larger than in the VIIRS Nightfire product. This is expected from the algorithmic difference and thought to more realistically represent e.g., large arrays of multiple gas flares.

Our methodology was also tested with a short time series of observations over an individual flaring site at Bovanenkovo on the Yamal peninsula in Siberia. Here, we compare near-coincidental overpasses of Sentinel-3A (SLSTR), TET-1 (HSRS) and Suomi-NPP (VIIRS). In terms of temperature, both SLSTR and HSRS show similar results, while VIIRS retrievals deliver slightly higher temperatures. Areas derived from SLSTR data are similar to those from VIIRS, and smaller than those from HSRS. In view of the inherent variability of the operation of gas flares, we consider those values, as well as the derived radiative power values, from the three instruments to be in good agreement.

The presented algorithm is suitable for the generation of an operational global gas flaring product from the series of Copernicus Sentinel-3 satellites. This requires the discrimination of gas flares from other persistent hot spots, which is possible with the data produced $[19,55]$. Based on the derived FRP of the gas flares, the product may also include estimates of the flared gas volume (BCM) and the emissions of black carbon and other smoke constituents.

Including the gas flaring emissions into the Copernicus Atmosphere Monitoring Service (CAMS) [61,62] would allow to simulate realistic black carbon deposition rates in the Arctic and quantify the corresponding albedo reduction and climate effects. This could be achieved by including black carbon emissions from a dedicated Sentinel-3 gas flaring product or by extending the Global Fire Assimilation System (GFAS, [63]) of CAMS to ingest and interpret also FRP from gas flaring as reported by VIIRS Nightfire and a future SLSTR Nightfire product.

Estimates of the temperatures of vegetation fires are also provided, albeit only at night-time. This is complementary to the burnt area and fire radiative products, which are currently being used 
for vegetation fire emission estimation, and carries a high potential for reducing some of the large uncertainties in these estimates.

Supplementary Materials: Supplementary Materials: The following are available online at http:/ /www.mdpi. com/2072-4292/10/7/1118/s1.

Author Contributions: Conceptualization, J.W.K., A.C. and G.R.; Methodology, A.C., J.W.K. and G.R.; Software, A.C. and D.L.; Validation, A.C., J.W.K., G.R., J.T., E.L. and O.F.; Formal Analysis, Investigation \& Resources, A.C., J.W.K. and G.R.; Data Curation, A.C., G.R., J.T., E.L. and O.F.; Writing-Original Draft Preparation, A.C.; Writing-Review \& Editing, J.W.K., G.R., E.L. and O.F.; Visualization, A.C.; Supervision, Project Administration \& Funding Acquisition, J.W.K. and G.R.

Funding: This research was funded by the German Federal Ministry for Economic Affairs and Energy (BMWi, Bundes Ministerium für Wirtschaft und Energie) under the constract number FKZ 50EE1339.

Acknowledgments: We would like to thank the two anonymous referees for their most helpful comments, which definitely improved the paper. G.R., J.T. and D.L. also acknowledge funding through BMWi under contract number FKZ 16KN052420.

Conflicts of Interest: The authors declare no conflict of interest. The founding sponsors had no role in the design of the study; in the collection, analyses, or interpretation of data; in the writing of the manuscript, and in the decision to publish the results.

\section{References}

1. Ismail, O.; Umukoro, G. Global Impact of Gas Flaring. Energy Power Eng. 2012, 4, 290-302, doi:10.4236/epe.2012.44039. [CrossRef]

2. Aghalino, S.O. Gas Flaring, Environmental Pollution and Abatement Measures in Nigeria, 1969-2001. J. Sustain. Dev. Afr. 2009, 11, 219-238.

3. Nwoye, C.I.; Nwakpa, S.O.; Nwosu, I.E.; Odo, J.U.; Chinwuko, E.C.; Idenyi, N.E. Multi-Factorial Analysis of Atmospheric Noise Pollution Level Based on Emitted Carbon and Heat Radiation during Gas Flaring. J. Atmos. Pollut. 2014, 2, 22-29, doi:10.12691/jap-2-1-5. [CrossRef]

4. Anomohanran, O. Determination of greenhouse gas emission resulting from gas flaring activities in Nigeria. Energy Policy 2012, 45, 666-670, doi:10.1016/j.enpol.2012.03.018. [CrossRef]

5. Ajao, E.A.; Anurigwo, S. Land-Based Sources of Pollution in the Niger Delta, Nigeria. Ambio 2002, 13, 442-445. [CrossRef]

6. Julius, O.O. Environmental impact of gas flaring within Umutu-Ebedei gas plant in Delta State, Nigeria. Arch. Appl. Sci. Res. 2011, 3, 272-279.

7. Obioh, I.; Oluwole, A.F.; Akeredolu, F.A. Non- $\mathrm{CO}_{2}$ gaseous emissions from upstream oil and gas operations in Nigeria. Environ. Monit. Assess. 1994, 31, 67-72. [CrossRef] [PubMed]

8. Uzomah, V.; Sangodoyin, A. Rainwater chemistry as influenced by atmospheric deposition of pollutants in Southern Nigeria. Environ. Manag. Health 2000, 11, 149-156, doi:10.1108/09566160010321569. [CrossRef]

9. Nwaichi, E.; Uzazobona, M. Estimation of the $\mathrm{CO}_{2}$ Level due to Gas Flaring in the Niger Delta. Res. J. Environ. Sci. 2011, 5, 565-572, doi:10.3923/rjes.2011.565.572. [CrossRef]

10. Onu, P.u.; Quan, X.; Ling, X. Acid rain: An analysis on the cause, impacts and abatement measures Niger Delta perspective, Nigeria. Int. J. Sci. Eng. Res. 2014, 5, 1214-1219.

11. European Commission, Joint Research Centre (JRC)/Netherlands Environmental Assessment Agency (PBL). Emission Database for Global Atmospheric Research (EDGAR), Release EDGARv4.2 FT2012. 2016. Available online: http:/ / edgar.jrc.ec.europa.eu/overview.php?v=42FT2012 (accessed on 29 June 2018).

12. Stohl, A.; Klimont, Z.; Eckhardt, S.; Kupiainen, K.; Shevchenko, V.P.; Kopeikin, V.M.; Novigatsky, A.N. Black carbon in the Arctic: The underestimated role of gas flaring and residential combustion emissions. Atmos. Chem. Phys. 2013, 13, 8833-8855, doi:10.5194/acp-13-8833-2013. [CrossRef]

13. Huang, K.; Fu, J.S.; Prikhodko, V.Y.; Storey, J.M.; Romanov, A.; Hodson, E.L.; Cresko, J.; Morozova, I.; Ignatieva, Y.; Cabaniss, J. Russian anthropogenic black carbon: Emission reconstruction and Arctic black carbon simulation. J. Geophys. Res. Atmos. 2015, 120, 11306-11333, doi:10.1002/2015JD023358. [CrossRef]

14. Quinn, P.K.; Shaw, G.; Andrews, E.; Dutton, E.G.; Ruoho Airola, T.; Gong, S.L. Arctic haze: Current trends and knowledge gaps. Tellus B 2007, 59, 99-114, doi:10.1111/j.1600-0889.2006.00238.x. [CrossRef] 
15. Doherty, S.J.; Warren, S.G.; Grenfell, T.C.; Clarke, A.D.; Brandt, R.E. Light-absorbing impurities in Arctic snow. Atmos. Chem. Phys. 2010, 10, 11647-11680, doi:10.5194/acp-10-11647-2010. [CrossRef]

16. Serreze, M.C.; Barry, R.G. Processes and impacts of Arctic amplification: A research synthesis. Glob. Planet. Chang. 2011, 77, 85-96, doi:10.1016/j.gloplacha.2011.03.004. [CrossRef]

17. Walsh, J.E. Intensified warming of the Arctic: Causes and impacts on middle latitudes. Glob. Planet. Chang. 2014, 117, 52-63, doi:10.1016/j.gloplacha.2014.03.003. [CrossRef]

18. Li, C.; Hsu, N.C.; Sayer, A.M.; Krotkov, N.A.; Fu, J.S.; Lamsal, L.N.; Lee, J.; Tsay, S.C. Satellite observation of pollutant emissions from gas flaring activities near the Arctic. Atmos. Environ. 2016, 133, 1-11, doi:10.1016/j.atmosenv.2016.03.019. [CrossRef]

19. Elvidge, C.D.; Zhizhin, M.; Baugh, K.; Hsu, F.C.; Ghosh, T. Methods for Global Survey of Natural Gas Flaring from Visible Infrared Imaging Radiometer Suite Data. Energies 2016, 9, 14, doi:10.3390/en9010014. [CrossRef]

20. Weyant, C.L.; Shepson, P.B.; Subramanian, R.; Cambaliza, M.O.L.; Heimburger, A.; McCabe, D.; Baum, E.; Stirm, B.H.; Bond, T.C. Black Carbon Emissions from Associated Natural Gas Flaring. Environ. Sci. Technol. 2016, 50, 2075-2081, doi:10.1021/acs.est.5b04712. [CrossRef] [PubMed]

21. Conrad, B.M.; Johnson, M.R. Field Measurements of Black Carbon Yields from Gas Flaring. Environ. Sci. Technol. 2017, 51, 1893-1900, doi:10.1021/acs.est.6b03690. [CrossRef] [PubMed]

22. Klimont, Z.; Kupiainen, K.; Heyes, C.; Purohit, P.; Cofala, J.; Rafaj, P.; Borken Kleefeld, J.; Schöpp, W. Global anthropogenic emissions of particulate matter including black carbon. Atmos. Chem. Phys. 2017, 17, 8681-8723, doi:10.5194/acp-17-8681-2017. [CrossRef]

23. Anejionu, O.C.; Blackburn, G.A.; Whyatt, J.D. Detecting gas flares and estimating flaring volumes at individual flow stations using MODIS data. Remote Sens. Environ. 2015, 158, 81-94, doi:10.1016/j.rse.2014.11.018. [CrossRef]

24. Zhang, X.; Scheving, B.; Shoghli, B.; Zygarlicke, C.; Wocken, C. Quantifying Gas Flaring $\mathrm{CH}_{4}$ Consumption Using VIIRS. Remote Sens. 2015, 7, 9529, doi:10.3390/rs70809529. [CrossRef]

25. Croft, T. Burning waste gas in oil fields. Nature 1973, 245, 375-376. [CrossRef]

26. Croft, T. Nighttime images of the earth from space. Sci. Am. 1978, 239, 86-98, doi:10.1038/scientificamerican0778-86. [CrossRef]

27. Elvidge, C.D.; Imhoff, M.L.; Baugh, K.E.; Hobson, V.R.; Nelson, I.; Safran, J.; Dietz, J.B.; Tuttle, B.T. Night-time lights of the world: 1994-1995. ISPRS J. Photogramm. Remote Sens. 2001, 56, 81-99, doi:10.1016/S0924-2716(01)00040-5. [CrossRef]

28. Elvidge, C.D.; Baugh, K.E.; Tuttle, B.T.; Howard, A.T.; Pack, D.W.; Milesi, C.; Erwin, E.H. A Twelve Year Record of National and Global Gas Flaring Volumes Estimated Using Satellite Data; Technical Report; World Bank: Washington, DC, USA, 2007.

29. Elvidge, C.D.; Ziskin, D.; Baugh, K.E.; Tuttle, B.T.; Ghosh, T.; Pack, D.W.; Erwin, E.H.; Zhizhin, M. A Fifteen Year Record of Global Natural Gas Flaring Derived from Satellite Data. Energies 2009, 2, 595-622, doi:10.3390/en20300595. [CrossRef]

30. Mota, B.W.; Pereira, J.M.C.; Oom, D.; Vasconcelos, M.J.P.; Schultz, M. Screening the ESA ATSR-2 World Fire Atlas (1997-2002). Atmos. Chem. Phys. 2006, 6, 1409-1424, doi:10.5194/acp-6-1409-2006. [CrossRef]

31. Oom, D.; Pereira, J. Exploratory spatial data analysis of global MODIS active fire data. Int. J. Appl. Earth Obs. Geoinf. 2013, 21, 326-340, doi:10.1016/j.jag.2012.07.018. [CrossRef]

32. Elvidge, C.D.; Baugh, K.E.; Ziskin, D.; Anderson, S.; Ghosh, T. Estimation of Gas Flaring Volumes Using NASA MODIS Fire Detection Products; Technical Report; NOAA National Geophysical Data Center: Boulder, CO, USA, 2011.

33. Faruolo, M.; Coviello, I.; Filizzola, C.; Lacava, T.; Pergola, N.; Tramutoli, V. A satellite-based analysis of the Val d'Agri Oil Center (southern Italy) gas flaring emissions. Nat. Hazards Earth Syst. Sci. 2014, 14, 2783-2793, doi:10.5194/nhess-14-2783-2014. [CrossRef]

34. Casadio, S.; Arino, O.; Serpe, D. Gas flaring monitoring from space using the ATSR instrument series. Remote Sens. Environ. 2012, 116, 239-249, doi:10.1016/j.rse.2010.11.022. [CrossRef]

35. Casadio, S.; Arino, O.; Minchella, A. Use of ATSR and SAR measurements for the monitoring and characterisation of night-time gas flaring from off-shore platforms: The North Sea test case. Remote Sens. Environ. 2012, 123, 175-186, doi:10.1016/j.rse.2012.03.021. [CrossRef] 
36. Elvidge, C.D.; Zhizhin, M.; Hsu, F.C.; Baugh, K.E. VIIRS Nightfire: Satellite Pyrometry at Night. Remote Sens. 2013, 5, 4423-4449, doi:10.3390/rs5094423. [CrossRef]

37. Anejionu, O.C.D.; Blackburn, G.A.; Whyatt, J.D. Satellite survey of gas flares: Development and application of a Landsat-based technique in the Niger Delta. Int. J. Remote Sens. 2014, 35, 1900-1925, doi:10.1080/01431161.2013.879351. [CrossRef]

38. Fisher, D.; Wooster, M.J. Shortwave IR Adaption of the Mid-Infrared Radiance Method of Fire Radiative Power (FRP) Retrieval for Assessing Industrial Gas Flaring Output. Remote Sens. 2018, 10, 305, doi:10.3390/rs10020305. [CrossRef]

39. Dozier, J. A Method for Satellite Identification of Surface Temperature Fields of Subpixel Resolution. Remote Sens. Environ. 1981, 11, 221-119. [CrossRef]

40. Brieß, K.; Bärwald, W.; Gill, E.; Kayal, H.; Montenbruck, O.; Montenegro, S.; Halle, W.; Skrbek, W.; Studemund, H.; Terzibaschian, T.; et al. Technology demonstration by the BIRD-mission. Acta Astronaut. 2005, 56, 57-63, doi:10.1016/j.actaastro.2004.09.041. [CrossRef]

41. Walter, I.; Briess, K.; Baerwald, W.; Lorenz, E.; Skrbek, W.; Schrandt, F. A microsatellite platform for hot spot dedection. Acta Astronaut. 2005, 56, 221-229, doi:10.1016/j.actaastro.2004.09.009. [CrossRef]

42. Zhukov, B.; Lorenz, E.; Oertel, D.; Wooster, M.; Roberts, G. Spaceborne detection and characterization of fires during the bi-spectral infrared detection (BIRD) experimental small satellite mission (2001-2004). Remote Sens. Environ. 2006, 100, 29-51, doi:10.1016/j.rse.2005.09.019. [CrossRef]

43. Oertel, D.; Briess, K.; Lorenz, E.; Skrbek, W.; Zhukov, B. Detection, monitoring and quantitative analysis of wildfires with the BIRD satellite. In Remote Sensing for Agriculture, Ecosystems, and Hydrology V, Proceedings of SPIE, Barcelona, Spain, 8-12 September 2004; Owe, M., D’Urso, G., Moreno, J.F., Calera, A., Eds.; SPIE: Bellingham, WA, USA, 2004; Volume 5232, pp. 208-218, doi:10.1117/12.511051.

44. Zhukov, B.; Briess, K.; Lorenz, E.; Oertel, D.; Skrbek, W. Detection and analysis of high-temperature events in the BIRD mission. Acta Astronaut. 2005, 56, 65-71, doi:10.1016/j.actaastro.2004.09.014. [CrossRef]

45. Reile, H.; Lorenz, E.; Terzibaschian, T. The FireBird Mission-A Scientific Mission for Earth Observation and Hot Spot Detection. In Proceedings of the Small Satellites for Earth Observation Digest of the 9th International Symposium of the International Academy of Astronautics, Berlin, Germany, 8-12 April 2013.

46. Coppo, P.; Ricciarelli, B.; Brandani, F.; Delderfield, J.; Ferlet, M.; Mutlow, C.; Munro, G.; Nightingale, T.; Smith, D.; Bianchi, S.; et al. SLSTR: A high accuracy dual scan temperature radiometer for sea and land surface monitoring from space. J. Mod. Opt. 2010, 57, 1815-1830, doi:10.1080/09500340.2010.503010. [CrossRef]

47. Coppo, P.; Mastrandrea, C.; Stagi, M.; Calamai, L.; Barilli, M.; Nieke, J. The Sea and Land Surface Temperature Radiometer (SLSTR) Detection Assembly design and performance. In Proceedings of the SPIE, Dresden, Germany, 16 October 2013; Meynart, R., Neeck, S.P., Shimoda, H., Eds.; SPIE: Bellingham, WA, USA, 2013; Volume 8889, doi:10.1117/12.2029432.

48. Cao, C.; Xiong, J.; Blonski, S.; Liu, Q.; Uprety, S.; Shao, X.; Bai, Y.; Weng, F. Suomi NPP VIIRS sensor data record verification, validation, and long-term performance monitoring. J. Geophys. Res. Atmos. 2013, 118, 11664-11678, doi:10.1002/2013JD020418. [CrossRef]

49. Reed, R.J. North American Combustion Handbook Vol. I: Combustion, Fuels, Stoichiometry, Heat Transfer, Fluid Flow; North American Manufacturing Company: Cleveland, OH, USA, 1986.

50. Leifer, I.; Lehr, W.J.; Simecek-Beatty, D.; Bradley, E.; Clark, R.; Dennison, P.; Hu, Y.; Matheson, S.; Jones, C.E.; Holt, B.; et al. State of the art satellite and airborne marine oil spill remote sensing: Application to the BP Deepwater Horizon oil spill. Remote Sens. Environ. 2012, 124, 185-209, doi:10.1016/j.rse.2012.03.024. [CrossRef]

51. Hilbig, T.; Weber, M.; Bramstedt, K.; Noel, S.; Burrows, J.P.; Krijger, J.M.; Snel, R.; Meftah, M.; Dame, L.; Bekki, S.; et al The new SCIAMACHY reference solar spectral irradiance and its validation. Sol. Phys. 2017, submitted.

52. Otsu, N. A Threshold Selection Method from Gray-Level Histograms. IEEE Trans. Syst. Man Cybern. 1979, 9, 62-66, doi:10.1109/TSMC.1979.4310076. [CrossRef]

53. Muirhead, K.; Cracknell, A.P. Identification of gas flares in the North Sea using satellite data. Int. J. Remote Sens. 1984, 5, 199-212, doi:10.1080/01431168408948798. [CrossRef]

54. Smith, D. Sentinel-3 SLSTR-Performance and Calibration. In Proceedings of the Sentinel-3 Validation Team Meeting, Darmstadt, Germany, 13-15 March 2018. 
55. Liu, Y.; Hu, C.; Zhan, W.; Sun, C.; Murch, B.; Ma, L. Identifying industrial heat sources using time-series of the VIIRS Nightfire product with an object-oriented approach. Remote Sens. Environ. 2018, 204, 347-365, doi:10.1016/j.rse.2017.10.019. [CrossRef]

56. Johnson, M.; Kostiuk, L. Efficiencies of low-momentum jet diffusion flames in crosswinds. Combust. Flame 2000, 123, 189-200, doi:10.1016/s0010-2180(00)00151-6. [CrossRef]

57. Leahey, D.; Preston, K.; Strosher, M. Theoretical and observational assessments of flare efficiencies. J. Air Waste Manag. Assoc. 2001, 51, 1610-1616. [CrossRef] [PubMed]

58. Johnson, M.; Kostiuk, L. A parametric model for the efficiency of a flare in crosswind. Proc. Combust. Inst. 2002, 29, 1943-1950, doi:10.1016/S1540-7489(02)80236-X. [CrossRef]

59. Ismail, O.S.; Umukoro, G.E. Modelling combustion reactions for gas flaring and its resulting emissions. J. King Saud Univ. Eng. Sci. 2016, 28, 130-140, doi:10.1016/j.jksues.2014.02.003. [CrossRef]

60. Pohl, J.H.; Tichenor, B.A.; Lee, J.; Payne, R. Combustion Efficiency of Flares. Combust. Sci. Technol. 1986, 50, 217-231, doi:10.1080/00102208608923934. [CrossRef]

61. Hollingsworth, A.; Engelen, R.J.; Benedetti, A.; Dethof, A.; Flemming, J.; Kaiser, J.W.; Morcrette, J.J.; Simmons, A.J.; Textor, C.; Boucher, O.; et al. Toward a Monitoring and Forecasting System for Atmospheric Composition: The GEMS Project. Bull. Am. Meteorol. Soc. 2008, 89, 1147-1164, doi:10.1175/2008BAMS2355.1. [CrossRef]

62. Stein, O.; Flemming, J.; Inness, A.; Kaiser, J.W.; Schultz, M.G. Global reactive gases forecasts and reanalysis in the MACC project. J. Integr. Environ. Sci. 2012, 9, 57-70, doi:10.1080/1943815X.2012.696545. [CrossRef]

63. Kaiser, J.W.; Heil, A.; Andreae, M.O.; Benedetti, A.; Chubarova, N.; Jones, L.; Morcrette, J.J.; Razinger, M.; Schultz, M.G.; Suttie, M.; et al. Biomass burning emissions estimated with a global fire assimilation system based on observed fire radiative power. Biogeosciences 2012, 9, 527-554, doi:10.5194/bg-9-527-2012. [CrossRef]

(C) 2018 by the authors. Licensee MDPI, Basel, Switzerland. This article is an open access article distributed under the terms and conditions of the Creative Commons Attribution (CC BY) license (http:/ / creativecommons.org/licenses/by/4.0/). 